\title{
MACHINE REPLACEMENT AND THE BUSINESS CYCLE: LUMPS AND BUMPS
}

\author{
Russell Cooper \\ John Haltiwanger \\ Laura Power
}

Working Paper 5260

\author{
NATIONAL BUREAU OF ECONOMIC RESEARCH \\ 1050 Massachusetts Avenue \\ Cambridge, MA 02138 \\ September 1995
}

\begin{abstract}
All three authors are research associates at the Center for Economic Studies, Bureau of the Census at which the empirical work for this project was conducted. We are most grateful to Mark Doms and Tim Dunne for sharing data with us and to Alok Johri for research assistance. Orley Ashenfelter, Paul Beaudry, Steve Berry, Ricardo Caballero, David Card, Zvi Eckstein, Douglas Gale, Simon Gilchrist, Zvi Hercowitz, Sam Kortum, Ariel Pakes, Michael Riordan and Mahlon Straszheim provided helpful comments and suggestions during this research. Financial support from the National Science Foundation and the Census Fellows Program is gratefully acknowledged. We thank seminar participants at the Board of Governors of the Federal Reserve System, Boston University, the Bureau of the Census, the European University Institute, Johns Hopkins, Harvard University, IGIER, Princeton University, Rice University, the University of Bologna, the University of Illinois, the University of Pennsylvania, the Stanford Institute for Theoretical Economics, the University of Wisconsin, Yale University and the NBER 1993 Summer Institute for helpful comments. This paper is part of NBER's research program in Economic Fluctuations. Any opinions expressed are those of the authors and not those of the National Bureau of Economic Research.
\end{abstract}

() 1995 by Russell Cooper, John Haltiwanger and Laura Power. All rights reserved. Short sections of text, not to exceed two paragraphs, may be quoted without explicit permission provided that full credit, including $\odot$ notice, is given to the source. 


\title{
MACHINE REPLACEMENT AND THE \\ BUSINESS CYCLE: LUMPS AND BUMPS
}

\begin{abstract}
This paper explores cyclical fluctuations in investment due to discrete changes in the plant's stock of capital. To do so, we focus on a machine replacement problem in which a producer decides whether to replace its entire existing stock of capital with new machinery and equipment. This decision is undertaken in a stochastic, dynamic environment which allows us to characterize the relationship between lumpy investment and the state of the aggregate economy. Our theoretical results are supplemented by numerical and empirical analyses of the dynamics of lumpy investment at the plant level and the associated aggregate implications. The dynamics are surprisingly rich since they represent the interaction between a replacement cycle, the cross sectional distribution of the age of the capital stock and the state of the aggregate economy. The empirical analysis of these dynamics is based on plant level investment data for the Longitudinal Research Database (LRD) for the 1972-91 period. Overall, we find that the frequency of lumpy investment activity is higher during periods of high economic activity and more likely the older is the capital. These empirical results are consistent with the predictions of our theoretical model. Nonetheless, the predicted path of aggregate investment that neglects the interaction of the non-flat hazard and the cross sectional distribution of the age of the capital stock tracks actual aggregate investment quite well. However, ignoring the fluctuations in the cross sectional distribution can yield predictable nontrivial errors in forecasting changes in aggregate investment in periods following large swings in aggregate investment.
\end{abstract}

Russell Cooper

Department of Economics

Boston University

270 Bay State Road

Boston, MA 02215

and NBER

Laura Power

Office of Tax Analysis

Department of Treasury

1500 Pennsylvania Avenue, NW

Washington, DC 20220
John Haltiwanger

Department of Economics

University of Maryland

College Park, MD 20742

and NBER 


\section{Machine Replacement and the Business Cycle: Lumps and Bumps}

\section{Introduction}

This paper investigates the aggregate implications of the non-convex adjustment of plant and equipment at the plant level. Our emphasis contrasts quite sharply with the neoclassical model of investment where the accumulation of capital reflects the slow adjustment of capital to its desired value. ${ }^{1}$ The model we pursue assumes that small adjustments of the capital stock are either not feasible or undesirable. In particular, many investment projects (eg. the construction of a new plant or the purchase of large machines) are not available in small quantities. Further, the costs of adjusting the capital stock may be non-convex, as described, for example, by Rothschild [1971]. As a consequence, at the plant level one may see periods of low investment activity followed by bursts of investment activity, i.e. investment spikes. Moreover, to the extent that these periods of high activity are not smoothed by aggregation, the non-convex cost of adjustment model may have interesting aggregate implications. ${ }^{2}$ In particular, the behavior of aggregate investment can be highly dependent on the cross sectional distribution of the age of the capital stock.

As documented further below, there are two key observations that motivate this view of investment activity. First, as reported by Doms and Dunne [1994], a significant fraction of investment activity at the plant level is associated with large variations in the capital stock:

\footnotetext{
1 This point is neatly seen in the transition path dynamics displayed by King, Plosser and Rebelo [1988] where the speed of adjustment to the steady state is largely determined by the curvature of the utility function. Abel [1990] provides a synthesis of the neoclassical investment model with convex adjustment costs. Abel and Eberly [1994] model the investment choice at the firm level allowing for fixed costs in the adjustment process in a stochastic environment. They provide conditions for inaction on investment due to these fixed costs of adjustment. Our emphasis is on the timing of discrete investment relative to the business cycle and the aggregation of discrete choices.

${ }^{2}$ For macroeconomists, this is a critical point. Bertola and Caballero [1990] discuss the role of aggregate shocks in creating synchronization of discrete decisions while Cooper and Haltiwanger [1992] stress the role of aggregate complementarities.
} 
i.e. investment is largely a lumpy activity. Second, aggregate variations in investment are associated with an increase in the frequency of investment spikes at the plant level. That is, investment activity at, the extensive margin plays a major role in aggregate investment behavior.

To better understand these observations, we construct a variant of the machine replacement model analyzed by Cooper and Haltiwanger [1993] in which individual plants decide upon the timing of machine replacement. Our earlier paper stressed deterministic cycles and argued that downturns were a good time for retooling since the opportunity costs were lower and, due to the deterministic cycles, an upturn in activity was sure to follow. In contrast, the emphasis here is on embedding the machine replacement problem in a dynamic stochastic environment. The theme that retooling should take place in periods of low activity must be qualified in this more general environment. The relationship between the gains to retooling and the state of the economy depends on the specification of the underlying stochastic process. Further, the costs of retooling depend on the nature of the adjustment cost specification: lump sum versus proportional costs. We find that recessions are not always the optimal time to retool. In particular, if shocks are persistent and adjustment costs are largely fixed, investment spikes are predicted to be procyclical.

Given these results on the optimal patterns of retooling at the individual plant level, we then investigate the implications of these discrete choices for aggregate investment. In light of the degree of heterogeneity in the microdata that we subsequently analyze, it is important to extend the analysis to a heterogenous plant setting. This allows us to understand the relationship between the cross sectional distribution of the age of the capital stock and the 
responsiveness of plant level and aggregate investment to aggregate shocks.

We use the LRD to investigate the predictions of the model in terms of the nature and timing of large scale investment episodes at the plant level and the connection between the latter and aggregate fluctuations in investment. The key result that emerges at the micro level is that the probability of a plant experiencing a large investment episode is increasing in the time since the previous episode. Thus, at the plant level, bursts of investment are then followed, on average, by periods of low investment. This is in contrast to the usual presumption of positive serial correlation in investment activities which emerges from the standard convex adjustment cost model. We demonstrate that, in terms of our hazard specification, the standard convex adjustment cost model yields a negatively sloped hazard. This prediction is conclusively rejected in the micro data.

While our estimated hazards are upward sloping, the predicted path of aggregate investment generated by ignoring the interaction of the non-flat hazard and the cross sectional distribution of the age of the capital stock tracks aggregate fluctuations in actual investment quite well. That is, investment movements are largely explained by factors other than the evolution of the cross sectional age distribution. However, ignoring the fluctuations in the cross sectional age distribution can yield predictable nontrivial errors in forecasting changes in aggregate investment after large swings in aggregate investment. It is during such periods that the cross sectional age distribution diverges substantially from the steady state distribution.

\section{A Machine Replacement Model}

Consider the problem of an individual producer with a given stock of capital. The 
productivity of this capital is influenced both by a shock to total factor productivity and the "age" of the capital. Given the state of productivity, the agent makes the discrete choice between replacing exișting capital with a new machine or continuing to use the capital for another period. In making its investment decision, the producer calculates the discounted expected benefits of more productive capital relative to the current costs of replacement. The gain to replacement is that a new piece of machinery is more productive as it reflects some aspects of technological progress. ${ }^{3}$ There are two types of costs of replacement. One is the direct loss of output associated with the acquisition and installation of new capital goods. Second, the process of installing the new machines and retraining workers reduces productivity in the plant. As we shall see, the nature of the adjustment costs and the structure of the stochastic process governing the shocks jointly determine the timing of replacement activity.

It should be noted at the outset that our specification focuses on lumpy investment by assumption. Thus our model fits into the ongoing literature on non-convex adjustment processes. $^{4}$

Formally, consider the optimization problem of an individual agent. Producer $\mathrm{i}=1,2, \ldots . . \mathrm{I}$ maximizes

\footnotetext{
${ }^{3}$ Hence this model stresses embodied technological progress as a source of growth.

- The recent paper by Caballero and Engel [1993a] provides a synthesis of one approach to this type of problem. In their model, the starting point of the analysis is a hazard function which depends on the difference between the current and target value of a particular variable, such as employment or capital. Their hazard function is thus a state dependent rule that may be parameterized and estimated and aggregate dynamics evaluated. This procedure has been used to characterize employment adjustments, Caballero and Engel [1993a] and Caballero, Engel and Haltiwanger [1995a], and to study invesunent flows, Caballero and Engel [1993b] and Caballero, Engel and Haltiwanger [1995b]. The current paper shares many themes with these other efforts though it characterizes a hazard function that depends on the time since last replacement (age of the capital) and the aggregate state rather than the deviation of the current variable from the target. Accordingly, there are some important differences across these approaches in terms of what the hazard function and the cross sectional distribution represent. As discussed in section IV below, the differences in approaches lead to quite different empirical strategies as well.
} 


$$
E_{0} \sum_{t=0}^{\ell=\infty} B^{t} u\left(C_{t}^{i}\right)
$$

subject to:

$$
\begin{aligned}
& C_{t}^{i}=Y_{t}^{i}=A_{t}^{i} \theta_{\imath}^{i} f\left(K_{t}^{i}\right)-z_{t}^{i} F_{t} . \\
& K_{t}^{i}=\left\{\begin{aligned}
(1-\delta) K_{t-1}^{i} & \text { if } \quad z_{t-1}^{i}=0 \\
\kappa_{t} & \text { if } z_{t-1}^{i}=1 .
\end{aligned}\right.
\end{aligned}
$$

where $\kappa_{1}=\mu \kappa_{t-1}$ and $\mu>1$ is the pace of exogenous technological progress. The choice variable in this problem is $z_{1}^{i}$ where $z_{1}^{i}=1$ means that replacement is chosen in period $t$.

The first equation is the objective function for the individual producer. In this simplified model, utility in a given period depends solely on consumption and labor time is fully utilized in the production process. Assume that $u(\cdot)$ is increasing and concave and that the discount rate $B \in(0,1)$. For much of the analysis, we will assume that $u(\cdot)$ is linear so that the agent's objective is to maximize the present value of output net of adjustment costs.

From the second equation, first note that consumption and (net) output are the same. This implies that the agent is unable to smooth consumption through the holdings of financial assets and/or inventories of the consumption good. The right side of (2) represents the production process, net of the adjustment costs. Gross output is an increasing function of the stock of capital, given by $f(\cdot)$ but also depends on the state of productivity, denoted by $A_{1}^{i}$, 
which contains an idiosyncratic and a common component. ${ }^{5}$

The production relation also includes the two costs of adjusting the capital stock described above. First, there is an opportunity cost associated with the diversion of labor and other inputs away from production and into adjustments in the capital stock. This is parameterized by $\theta_{\mathrm{t}}^{\mathrm{i}}$ which equals 1 during non-replacement periods and equals $\lambda<1$ during each replacement period. ${ }^{6} \quad$ Second, there is a fixed cost of adjustment given by $\mathrm{F}_{\mathrm{t}} \mathrm{z}_{\mathrm{t}}^{\mathrm{i}}$ which reflects both the lost output from the acquisition of the new capital and other fixed adjustment costs, where $z_{t}^{i}=1$ iff replacement is occurring in period $t$.

The final equation expresses the time path of capital and hence its link to the producer's choice. We denote by $\kappa_{\mathrm{t}}$ the leading edge technology; however, each producer's actual capital $\left(K_{J}\right)$ is generally not the best technique available. In every period, the producer has the choice of replacing its current machine with the leading technology. ${ }^{7}$ If the producer chooses replacement $\left(z_{i}^{i}=1\right)$, then the adjustment costs described above are borne in period $t$ and the producer's capital in the next period is $k_{t+1}$. If the producer chooses not to replace then the machine depreciates at rate $\delta .^{8}$ Note then that the gains to replacement reflect both the pace of technological progress $(\mu)$ and the rate of physical depreciation of a machine $(\delta)$.

There are three interpretations of this optimization problem. The most direct is that

\footnotetext{
- That is, assume $A_{1}^{i}=A_{1} c_{t}^{i}$. Of course, at this point in the analysis this distinction is not important. It will become very relevant for understanding the aggregate implications of this model. While we consider a model with technology shocks, one could instead consider an economy in which the shocks to the production process represent changes in relative product demands either across producers or over time.

- Note that this naturally implies heterogeneity in adjustment costs across firms if $\lambda<1$, a point emphasized by Caballero and Engel [1993b] as well.

'For simplicity we assume that the replacement process renders previous vintages worthless both in the plant and to others. The model could be supplemented to allow for the interaction of multiple vintages or a resale market for used capital. Further, the replacement decision is irreversible.

- The model could be easily supplemented to allow for some small leveis of investment (e.g. to replace broken machines and so forth) even when large investments are not taking place.
} 
the economy consists of I independent producers financing investment from their own output and consuming the remainder. A second interpretation comes from the centralized problem of a planner making machine replacement decisions at I sites with a representative agent consuming the difference between output and investment. In the case of linear utility, the choices across sites are independent and (1)-(3) (with utility linear) would then represent the planner's problem at one of the sites. When utility of the representative agent is strictly concave, our formulation misses the congestion effects that would arise in the planner's problem. Finally, when $u(c)=c$ in (1), this specification is equivalent to a partial equilibrium problems in which I firms maximize the discounted present value of revenues net of investment expenses.

The underlying exogenous technological progress in this economy makes this into a non-stationary problem. For our analysis, it is convenient to consider a stationary version of this economy. In particular, we assume that $u\left(C_{t}\right)=C_{t}^{1-\gamma} / 1-\gamma$ and $f(\cdot)$ exhibits constant returns to scale. Let $\mathrm{X}_{t}=\mathrm{X}_{\mathrm{t}} / \kappa_{\mathrm{t}}$ so that lower case letters represent values which are normalized by the current value of the leading technology. Further, suppose that the fixed cost of installing the capital is proportional to the leading edge technology, i.e. $F_{1}=F_{\kappa_{1}}$. Then, the economy described in (1)-(3) can be rewritten as

$$
E_{0} \sum_{t=0}^{t=\infty} \beta^{\prime} u\left(c_{t}^{i}\right)
$$

subject to:

$$
c_{t}^{i}=y_{\imath}^{i}=A_{t}^{i} \theta_{t}^{i} k_{t}^{i}-z_{t}^{i} F
$$

In this version of the optimization problem, note that the discount rate $\beta$ is different from 


$$
k_{t}^{i}=\left\{\begin{array}{rr}
\rho k_{t-1}^{i} & \text { if } z_{t-1}^{i}=0 \\
1 & \text { if } z_{t-1}^{i}=1
\end{array}\right.
$$

that used in (1). This reflects the fact that in dividing through by $\kappa_{t}$, the rate of technical progress $\mu$ as well as the parameters of preference and technology influence the discount rate. This has an interesting implication for empirical work in that across sectors with different rates of technological progress, one ought to find different rates of discounting and hence differences in the solution to the machine replacement problem. We assume that the rate of technological progress $(\mu)$ is not too big so that $\beta<1 .{ }^{9}$ In $(6), \rho=(1-\delta) / \mu$ and lies between zero and one and reflects both physical depreciation and obsolescence. With our normalization, machine replacement $\left(z_{1}^{i}=1\right)$ implies that the state of the machine is 1 in the next period; otherwise, the capital is only a fraction $\rho$ of its size in the previous period.

To analyze this problem, we utilize a dynamic programming approach where the value function $V(k, A)$ satisfies the following functional equation:

$$
V(k, A)=\max \left[u(A f(k))+\beta E_{A^{\prime}, A} V\left(\rho k, A^{\prime}\right), u(A f(k) \lambda-F)+\beta E_{A^{\prime} A^{\prime}} V\left(1, A^{\prime}\right)\right]
$$

where the expectation is taken using the conditional distribution, $\Phi\left(A^{-} \mid \mathbf{A}\right)$. The current aggregate shock plays two roles in this dynamic programming problem. First it has a direct influence on current productivity and second it is informative about future productivity through $\Phi\left(A^{\prime} \mid A\right)$.

Our first result is the existence of a solution to this functional equation. Proofs of

\footnotetext{
'In going from (1) to (4) we use the fact that $\frac{C_{t}^{1-\gamma}}{1-\gamma}=x_{t}^{1-\gamma} \frac{c_{t}^{1-\gamma}}{1-\gamma}=x_{0}^{1-\gamma} \mu^{(1-\gamma)} \frac{c_{t}^{1-\gamma}}{1-\gamma}$. From this, $\beta^{t}=\left(B_{\mu}^{1-\gamma}\right)^{r}$ and we assume that $B \mu^{1-\gamma}<1$.
} 
this and other propositions are in the appendix.

Proposition 1: There exists a solution to the functional equation.

We represent the solution to (7) through a hazard function $H(k, A)$, which is the probability of replacing if the current capital stock is $\mathrm{k}$ and the aggregate state of productivity is $\mathrm{A}$. The hazard function provides an ideal link between the theory and the empirical exercises since it neatly summarizes the theoretical implications and can be estimated from the data. Note that the hazard function conditions on the aggregate state only, assuming that the idiosyncratic part of the shock is not observable to the econometrician. ${ }^{10}$ Thus $H(k, A) \epsilon[0,1]$ while if we condition on both the aggregate and idiosyncratic components, then the hazard would either be zero or one.

The policy rules for this problem reflect two forces: an underlying replacement cycle and the response of the agent to shocks in productivity. For the non-stochastic version of this problem, Cooper and Haltiwanger [1993] find there will be a deterministic replacement cycle in which the time between replacement will depend, inter alia, on the proportional and fixed costs of adjustment, $\lambda$ and $F$.

In the stochastic case, this underlying deterministic cycle will imply that the older the capital, the more likely is replacement: $H(k, A)$ is decreasing in $k$. This is shown in Proposition 2 below, though only with some restrictions on the size of $F$ and the curvature of $u(\cdot){ }^{11}$ Further, the replacement decision will be influenced jointly by the realized value of

\footnotetext{
10 Again, our ultimate goal is to relate the model to microeconomic evidence in which we will be unable to observe all aspects of plant productivity. So, in conducting that analysis, we will condition on the state of the aggregate economy. Thus, it is useful to derive theoretical results that pertain to that exercise. If we write the hazard over $k$ and the decomposed shock as $H(k, A, \varepsilon)$, then the hazard we work with. $H(k, A)$, is the integral of $H(k, A, \varepsilon)$ over the fixed distribution of $\varepsilon$. Since this is an iid shocks, its distribution is independent of the distribution of $\mathbf{k}$.

1 When $\left.\mathbf{u}^{-}\right)$is strictly concave and $\mathrm{F}$ large, then the costs of replacement could be lower for high values of $k$ implying the possibility that the hazard is not strictly increasing. In this case our method of proof seems to fail.
} 
the technology parameter and the age of the capital stock. The response of investment to this random variable depends on both the nature of the adjustment costs ( $\lambda$ and F) and the persistence of the shock. The agent would prefer to replace machines during a period where inputs are not very productive (reflecting $\lambda<1$ ) and would also prefer to have a new machine available when productivity is high. At one extreme, if the adjustment costs are just a fixed cost of replacement, then the strict concavity of $u(\cdot)$ will imply that replacement is more likely during economic upturns when consumption is high; i.e. $\mathrm{H}(\mathrm{k}, \mathrm{A})$ is increasing in A. This is the point of Proposition 3 below. On the other hand, if the adjustment costs are proportional to output, then the opportunity cost argument implies that replacing investment in good times is quite costly; i.e. $\mathrm{H}(\mathrm{k}, \mathrm{A})$ is decreasing in A. Proposition 4 verifies this claim in the case of iid shocks as long as $u(\cdot)$ is not too concave. In this proposition, we restrict the relative risk aversion measure for $u(\cdot)$, denoted by $R(\cdot)$ to be less than one at all points in the consumption space. Finally, Proposition 5 shows that if shocks are positively serially correlated and adjustment costs are lump sum, then replacement investment is procyclical since expected benefits are higher due to the persistence in $\mathrm{A}$.

Proposition 2: If $u(\cdot)$ is not too concave and $F$ is small, then $H(k, A)$ is decreasing in $k$.

Proposition 3: If $u(\cdot)$ is strictly concave, $F>0, \lambda=1$ and $A$ is iid, then $H(k, A)$ is increasing in A.

Proposition 4: If $R(\cdot)<1, F=0, \lambda \epsilon(0,1)$ and $A$ is iid, then $H(k, A)$ is decreasing in $A$.

Proposition 5: If $u(\cdot)$ is linear, $F>0, \lambda=1$ and $\Phi\left(A^{-} \mid A\right)$ is decreasing in $A$, then $H(k, A)$ is increasing in $\mathrm{A}$.

\section{Simulations}


Obtaining analytic solutions to the stochastic dynamic programming problem to study the aggregate implications of the replacement decision at the producer level is quite difficult. This reflects an inability to obtain a closed form decision rule for the individual producer and thus dealing with the heterogeneity across multiple producers. So, to better understand the implications of the solution to this problem for aggregate investment, we have produced simulation results. ${ }^{12}$

\section{A. Approach and Individual Optimization Results}

For the numerical analysis, we solved the dynamic programming problem given in (7) using value function iteration. The state space had three components. First, the capital stock lies in the discrete set given by $\left\{1, \rho, \rho^{2}, \rho^{3}, \ldots\right\}$ where $\rho$ reflects both depreciation and obsolescence. Second, we assume that there are two aggregate shocks $\left\{A_{H}, A_{L}\right\}$ with $A_{H}>A_{L} \cdot{ }^{13}$ Third, we assume that the idiosyncratic shocks take values in a discrete set. ${ }^{14}$ The idiosyncratic shocks are important to the analysis since they generate a non-degenerate distribution of the capital stock. Further, they are a dominant element in any empirical study of investment and so must appear in the theoretical model.

For the simulations, we assume that the rate of capital depreciation $(\delta)$ is .1 , the discount rate for the agent (B) is .9 and the technological progress parameter $(\mu)$ is 1.00 . Further, assume that utility is a linear function of consumption. The aggregate shock is determined by a first order Markov process where $\operatorname{Prob}\left(A_{t+1}=A_{j} \mid A_{t}=A_{j}\right)=.9$ for $j=L, H$.

\footnotetext{
12 This approach is also complementary to our objective of estimating the parameters of the problem from microeconomic data, a topic we return to in our discussion of empirical evidence.

13 For the simulations, $A_{L}=.75$ and $A_{H}=1.25$.

14 The idiosyncratic shocks were multiplicative and took on 20 values between .4 and 1.6, with a mean of one. Throughout our experiments, these shocks were iid.
} 
Since we have set $\mu=1, \rho=(1-\delta)$ and $\beta=B=.9$. The fixed cost $(F)$ is set at .2 and the opportunity cost of replacement $(1-\lambda)$ is .25 .

Figure 1 presents the hazard functions for this economy conditional on the aggregate state. Instead of reporting the hazard for a given $\mathrm{k}$, the horizontal axis measures the time since last replacement. Thus, from Proposition 2, the hazard is increasing in the time since last replacement, given $A$. In the discussion that follows, we term this an "increasing hazard" to focus on the relationship between the probability of replacement and the time since last replacement given $A .^{15}$

For this simulation, the hazard is upward sloping in accord with Proposition 2. Further, as an illustration of Proposition 5, the combination of fixed costs and persistent shocks implies a procyclical hazard. Since the cost of change is independent of the state of productivity, it is optimal to replace during upturns to take advantage of the complementarity between the state of total factor productivity and the age of the capital.

B. Aggregate Investment

One of our primary motivations is to provide a link between discrete investment choices at the producer level and aggregate investment. That relationship is greatly enriched by the interaction of aggregate shocks and underlying heterogeneity across plants. To make this point, we study each effect in isolation and then focus on their interaction. Throughout this section, we use the parameters described earlier.

Before proceeding, it is useful to have a specification for the evolution of the capital stock and a measure of aggregate investment. Denote by $g_{\mathrm{t}}(\mathrm{k})$ the period $\mathrm{t}$ cross sectional

\footnotetext{
19 Still, the hazard depends on the two state variables $(k, A)$ along with the idiosyncratic shock and thus should not be confused with a deterministic time dependent policy function.
} 
distribution of capital, indexed by vintage (k). The aggregate level of investment in period $t$, given an aggregate shock $(\mathrm{A})$, is

$$
I_{l}(A)=\Sigma_{k} H(k, A) g_{l}(k)
$$

To understand this expression, consider a given vintage of capital. For that vintage and aggregate productivity $A$, the hazard $H(k, A)$ is the probability of investment. Summing this over $\mathrm{k}$, weighted by the fraction of producers in each state, yields aggregate investment. ${ }^{16}$ From this expression, aggregate investment is determined jointly by the cross sectional distribution as well as by the current state of productivity. Of course, the importance of the cross sectional distribution is dependent upon the shape of the hazard function. Clearly, if $H(k, A)$, is independent of $k$, then the aggregate level of investment is independent of $g(k)$.

This accounting framework highlights the two influences on aggregate investment: shifts in the hazard and movements along a fixed hazard due to changes in the cross sectional distribution. The key issue in the empirical analysis is disentangling these two forces.

The evolution of the cross section distribution is given by

$$
\begin{gathered}
g_{t+1}(1)=I_{t}(A) \\
g_{t+1}(\rho k)=[1-H(k, A)] g_{t}(k) .
\end{gathered}
$$

where $I_{t}(A)$ is given above. Thus the fraction of agents with new capital, $k=1$, is simply the investment rate in a given period. Further, the fraction with capital of vintage $\rho \mathrm{k}$ in period $t+1$ is the fraction of producers with capital $k$ in period $t$ who choose not to invest.

A neat way to visualize the evolution of the cross section distribution is given in Figure 2. Here the state space is depicted as a ladder. Producers on a particular rung in

\footnotetext{
is Recall that there is no choice on the size of investment so that we normalize a "project" to be an investment level of 1 .
} 
period $t$ either go to the top of the ladder with probability $H(k, A)$ (i.e. they invest) or move down one rung with probability $1-\mathrm{H}(\mathrm{k}, \mathrm{A})$. For a fixed value of $\mathrm{A}$, the cross sectional distribution will evolve to a stationary distribution. Aggregate shocks disrupt this process so that the resulting time path of investment reflects the response of investment to these shocks and the dynamics of the adjustment process of the cross sectional distribution.

To better understand the underlying dynamics of this economy, consider first an extreme case in which there are no aggregate shocks in the system. The presence of the idiosyncratic shocks will lead to a nondegenerate distribution of the capital stock across agents. However, there will be no aggregate dynamics in that the economy will settle on a steady state distribution.

Figure 3 displays the behavior of aggregate investment starting from a uniform distribution of producers across the capital state space in an economy without aggregate uncertainty. Initially there is a burst of investment since many producers have old capital as their initial condition. Over time the distribution evolves until a stationary distribution is obtained and the level of aggregate investment is constant. Note that the adjustment dynamics lead to cycles in aggregate investment. Each producer undertakes machine replacement at stochastic intervals of time: the deterministic machine replacement system is made stochastic by the producer specific shocks. Yet, due to the assumed large number of plants, the economy has a stationary distribution with constant aggregate investment.

Consider now the other extreme in which there are only aggregate shocks to the system. In this case all fluctuations in aggregate investment are driven by these shocks. As there is no heterogeneity, initial differences in the age of capital disappear over time as 
replacement becomes synchronized due to the common shocks. ${ }^{17}$

The most interesting case, of course, arises when there are both aggregate and idiosyncratic shocks. This is clearly the empirically relevant case since differences across plants given the state of the aggregate economy are quite significant. ${ }^{18}$ Furthermore, it is the interaction between the cross section distribution and the aggregate state that gives rise to such rich dynamics in the machine replacement problem. Note that when both types of shocks are present, the economy will have fluctuations in aggregate investment as well as a non-degenerate cross sectional distribution of the capital stock.

A simulation in which there are two aggregate states and idiosyncratic shocks is displayed in Figure 4. In this figure, the aggregate state is either 0 (corresponding to $A_{t}=A_{L}$ ) or 1 (corresponding to $A_{t}=A_{H}$ ). Note that investment spikes when the aggregate state changes from low to high. However, these spikes are not of uniform height since the fraction of investors depends on the underlying distribution. This is one way in which the cross sectional distribution influences aggregate investment. Furthermore, between variations in the aggregate state, the economy experiences cycles in investment. This is similar to the pattern portrayed in Figure 3 as the economy converged to a stationary distribution. In an economy with both idiosyncratic shocks and aggregate shocks, these same transition dynamics govern the system between the switches in the aggregate state.

\section{Empirical Evidence on Investment Patterns}

\section{A. Measurement and Basic Facts}

\footnotetext{
17 This is the type of synchronization described in Bertola and Caballero [1990].

in We discuss the empirical evidence on plant level heterogeneity in some detail in the next section.
} 
The data used to evaluate the predictions of our theory are longitudinal data for 6900 plants in the U.S. manufacturing sector for the period 1972-91. The data are a subset of the Longitudinal Research Database (LRD) representing all large, continuously operating manufacturing plants over the sample. While entry and exit are obviously of interest in this context, in this study we focus our effort on the continuously operating plants. This permits a detailed examination of the empirical investment hazard at the plant level and its connection to aggregate fluctuations in investment.

Our objectives are threefold: (i) to characterize large scale investment episodes at the plant level, (ii) to determine whether there is a systematic relationship in the timing of large investment episodes at the plant level in a manner consistent with the machine replacement model and (iii) to quantify the connection between the timing of large investment episodes at the plant level and aggregate fluctuations in investment. In pursuing these objectives, we evaluate the predictions of our theory model relative to the predictions from the standard alternative model, the convex adjustment cost model.

Three recent studies (Doms and Dunne [1994], Power [1994], and Caballero, Engel and Haltiwanger [1995b]) have used the LRD to study the process of plant level investment. Doms and Dunne conduct an exploratory data analysis characterizing the distributions of plant level investment. For their 16 year sample (which is quite similar to ours), they find that plants concentrate about $50 \%$ of their cumulative 17 year investment in the three years surrounding the year with the largest investment. Power [1994] conducts an exploratory study of the timing of the large investment episodes and in this regard we build upon her work. Caballero, Engel and Haltiwanger [1995b] exploit the adjustment hazards approach 
developed by Caballero and Engel [1993a]. In this context, the latter approach involves estimating the plant-level relationship between investment and an estimate of the difference between the actual and desired capital stock. ${ }^{19}$ None of these papers address the issues that are the focus of this paper: the timing of large investment episodes at the plant level and the connection between the timing of large investment episodes at the plant level and aggregate fluctuations in investment.

To begin our empirical analysis, we first address the representativeness of our sample and then characterize the basic properties of the cross sectional distribution of plant level investment in our sample. The top panel in Figure 5 depicts aggregate gross and net investment in machinery and equipment for the U.S. manufacturing sector over this period based upon tabulations from the 4-digit Annual Survey of Manufactures published data. The gross investment is deflated at the 4-digit level with investment price deflators (in 1987 dollars) and the net investment series is tabulated using BEA 2-digit depreciation rates and the perpetual inventory method. The lower panel in Figure 5 depicts the same series based upon our sample of 6900 plants. For the latter, we initialized the real capital stock for each plant in 1972 by multiplying the book value of machinery in 1972 by the ratio of real to book value of the machinery for the 2-digit industry in which the plant operates in 1972 . Even though we only have a small fraction of the total number of plants, the gross investment in machinery for our sample constitutes about $45 \%$ of aggregate investment in machinery. Most importantly for our purposes, the correlation between aggregate investment

\footnotetext{
19 Since the Caballero, Engel and Haltiwanger [1995b] (hereafter CEH) approach requires constructing a measure of the desired capital stock this generates substantial differences in the empirical approach to the data to that pursued here. The advantage of the CEH approach is that this permits rich characterization of the driving forces of aggregate investment fluctuations (e.g., aggregate shocks, idiosyncratic shocks, cost of capital shocks and their respective interactions with nonlinear response at the micro level). The advantage of the approach pursued here is that measurement/specification error issues play less of a role since we focus on timing patterns.
} 
and investment measured in our sample is quite high. Thus, though we focus on a subset of the producers, their investment behavior seems representative of total manufacturing.

Figure 6 depicts a histogram of annual plant-level gross investment rates. ${ }^{20}$ The distribution is highly skewed to the right. The large fraction of plants with investment rates at or near zero reflects the fact that many plant-year observations involve little or no investment. For our data set, about $10 \%$ of the observations entail a zero level of investment. The long right tail illustrates the fact that a relatively small, but important, fraction of plants experience a large investment episode in any given year.

To evaluate the contribution of the largest investment episodes to aggregate investment, we rank the investment rates for each plant over the 20 year sample period and examine the contribution of the plant level ranked episodes to cumulative aggregate investment over the 20 year period. ${ }^{21}$ Figure 7 depicts the results of this exercise. Using only the investment associated with the largest investment episode for each plant yields $17 \%$ of cumulative aggregate investment. The top five investment years at each plant account for more than $50 \%$ of cumulative aggregate investment. ${ }^{22}$

To provide some perspective on the time series fluctuations and relative importance of large investment episodes, Figure 8 depicts the time series fluctuations in the fraction of plants with gross investment rates in excess of $20 \%$ and the contribution of such plants to

\footnotetext{
20 All plant-year observations are used to constuct Figure 6. The gross investment rate is measured as the real gross machinery investment in the period divided by the initial real value of the machinery in the period.

21 By cumulative aggregate investment we mean the sum of all investment for all plants and all years for our sample.

22 These results appear to differ somewhat quantitatively (although not qualitatively) from the results by Doms and Dunne [1994]. That is, they find that the largest investment episode at each plants accounts for $25 \%$ of cumulative investment over their sample for the typical plant. However, this primarily reflects differences in the length of our samples (their sample is 17 years, ours is 20 years). The difference in the length of the sample will by construction yield differences in the contribution of the largest investment episode to cumulative investment over the sample.
} 
aggregate investment. The aggregate gross investment rate is plotted for comparison on the right vertical axis. A number of observations are worth making. First, plants with large investment episodes constitute about $20 \%$ of the plants but account for almost $50 \%$ of gross investment. The latter is a large percentage but far from $100 \%$-- that is, both lumpy and non-lumpy investment are important components of investment. Second, the fraction of plants having large investment episodes and the amount of investment accounted for by such plants is positively correlated with the aggregate investment rate. ${ }^{23}$ This is important because much of the subsequent analysis is about the determinants of plants having large investment episodes and the cyclical fluctuations in such plants. These findings indicate that factors driving aggregate investment are closely linked to factors driving the fraction of plants experiencing large investment episodes.

\section{B. Motivating Our Empirical Approach}

The evidence in Figures 6,7 and 8 is only suggestive since we cannot a priori rule out the hypothesis that the observed skewed distribution of plant level investment reflects a skewed distribution of idiosyncratic shocks impacting plants. To distinguish this hypothesis from the lumpy investment model, we investigate the timing of the relationship between the large investment episodes at the plant level.

Our machine replacement model of section II predicts an upward sloping hazard with respect to the time since last replacement. In practice, we investigate this prediction by examining whether the probability of having a large investment episode at the plant level is increasing in the time since the last large investment episode.

\footnotetext{
23 The correlation between the aggregate investment and the fraction of plants with investment larger than $20 \%$ is 0.57 . The correlation between aggregate investment and the fraction of investment accounted for by plants with investment greater than $20 \%$ is 0.69 .
} 
The competing hypothesis that the skewed distribution of plant level investment simply reflects the skewed distribution of idiosyncratic shocks does not imply an upward sloping hazard. In the face of serially uncorrelated random shocks and no adjustment costs, the hazard should be flat with respect to the time since the last large investment episode. The presence of serially correlated random shocks or convex adjustment costs implies plantlevel investment will be positively serially correlated and thus the hazard should be downward sloping.

To examine this point further, consider a simple convex cost of adjustment model in which a firm maximizes the discounted present value of profits (I) where $\Pi=\theta \mathrm{K}-1 / 2 \gamma I^{2}$, where $\mathrm{K}$ is the stock of capital, $\theta$ is the state of productivity and $\mathrm{I}$ is the level of investment. The flow of profits is equal to the flow of output from the capital less the quadratic costs of adjusting the capital stock. The capital stock is assumed to depreciate at a rate of $\delta \in(0,1)$. The solution to this dynamic optimization problem is $\mathrm{I}=\mathrm{a}+\mathrm{b} \theta$, where $\mathrm{a}$ and $\mathrm{b}$ are constants that depend on the parameters of the problem including those that characterize the stochastic process for $\theta$.

Figure 9 illustrates the results of simulating this model assuming that $\theta$ is positively serially correlated. ${ }^{24}$ The investment rate (vertical axis) fluctuates due to variations in the productivity of capital and with enough dispersion in $\theta$, investment rate spikes can emerge. Note, however, that these investment spikes occur in bunches, reflecting the persistence in $\theta$ implying that the probability of large investment in the current period is higher if there was an investment spike in the previous period. That is, the hazard is downward sloping. In the

\footnotetext{
${ }^{34}$ For these simulations, the discount rate was set at .9 , the rate of depreciation at .1, the serial correlation in $\theta_{1}$ was set at .9 and $\gamma$ was normalized at 1.
} 
next section, we elaborate further on the contrasting predictions of our machine replacement model and alternatives such as this simple convex adjustment cost model.

C. Defining An Investment Spike

Our objective is to examine the timing of large investment episodes at the plant level. To accomplish this objective, we must develop a method for defining a large or lumpy investment episode. That is, unlike the specification of the theoretical model, not all positive investment episodes are easily categorized as representing a lumpy investment episode.

To address this difficulty, we consider alternative methods of defining lumpy investment episodes -- hereafter denoted as investment spikes. Three definitions of investment spikes are considered as follows:

(i) Relative threshold: investment spike if gross investment rate at plant in year is 2.5 times median annual gross investment for plant over entire sample period;

(ii) High absolute threshold: investment spike if gross investment rate at plant in year is greater than $20 \%$;

(iii) Low absolute threshold: investment spike if gross investment rate at plant in year is greater than $3 \%$;

All three definitions attempt to define a threshold investment rate above which a plant is incurring the adjustment costs and machine replacement process that are the focus of the model. The first definition is that used by Power [1994]. ${ }^{25}$ It reflects the idea that abnormally high investment episodes are defined relative to the typical investment rate experienced within a plant. The second definition is similar but uses an absolute rather than a relative threshold. The third approach takes a somewhat different view based upon the

\footnotetext{
23 Power [1994] considers the robustness of her results to alternative relative thresholds. In particular, she considers 1.75, 2.5 and 3.25 times the median. Her findings are, for the most par, robust to these alternative definitions of investment spikes.
} 
alternative hypothesis that virtually all positive investment episodes involve incurring the adjustment costs of undergoing machine replacement. In this case, investment rates of less than $3 \%$ are interpreted as representing investment that does not induce the fixed costs that are the focus of the model.

The definitions of these thresholds encompass varying views of the lumpy and nonlumpy components of investment. We proceed by investigating the timing relationship between investment spikes so defined. Recall that our model predicts an upward sloping hazard in the time since the last spike while Figure 9 implies that the hazard will be downward sloping if the defined spikes only represent large (potentially serially correlated) shocks in the presence of convex adjustment costs. A natural question is the sensitivity of these contrasting predictions to the alternative definitions of investment spikes. Figure 9 implies that the prediction of a downward sloping hazard from the convex adjustment model is not sensitive to the specific threshold chosen to define an investment spike. That is, the prediction of a downward sloping hazard from convex adjustment cost model with positively serially correlated shocks is consistent with any threshold definition.

The impact of the threshold on the predictions from the machine replacement model is somewhat more difficult to evaluate. On the one hand, choosing too low a threshold implies that some of the observed spikes may represent non-lumpy investment that does not exhibit the timing patterns predicted by the machine replacement model. On the other hand, choosing too high a threshold implies that some machine replacement episodes may be excluded from the spike definitions. In both cases, there is potential measurement error in both the dependent and independent variables which would bias the estimated hazard. 
Evaluating the magnitude of such biases requires imposing structure well beyond the scope of this paper. Instead, the approach here is to consider alternative investment spike definitions to characterize the sensitivity of the results to these concerns.

To sum up our empirical approach, distinguishing between competing hypotheses of large scale investment episodes is based on examining the slope of the estimated hazards for the alternative spike definitions. A finding of a flat hazard is consistent with a random shock, no adjustment costs model and a finding of a downward sloping hazard is consistent with the convex adjustment cost model. With these remarks and caveats in mind, we now proceed to use these spike definitions to estimate the hazards and investigate the aggregate implications.

\section{Kaplan-Meir Estimates of Investment Hazard}

We begin our characterization of the timing relationship between large investment episodes by examining the Kaplan-Meir nonparametric hazards for each investment spike definition. Kaplan-Meir estimates are generated from the pooled 1980-91 sample as well as for individual years. ${ }^{26}$ Figure 10 depicts the Kaplan-Meir hazards for specific years and for the pooled sample. The empirical hazards exhibit pronounced shifts across years that are non-neutral across investment ages. For each spike definition, the Kaplan-Meir hazard is decreasing in the time since the last investment spike. This result holds true for the estimates based on the pooled sample across years as well as the by year estimates. The sharpest decline in the probability of having an investment spike occurs after investment age zero

\footnotetext{
26 To minimize the impact of censoring in the subsequent estimation, we focus our attention on the period 1980-91. This permits nine investment age categories (0-8) where age 0 in a given year represents plants that had an investment spike in the previous period and age 8 represents plants that have not experienced an investment spike in the previous eight years.
} 
(i.e., plants who had a spike in the previous period). The large probability associated with having a spike in the period immediately following a spike reflects the multiyear spike phenomenon emphasized in the findings of Doms and Dunne [1994]. That is, one of their key findings is that large investment episodes are often spread across two (or sometimes three) years. While this multiyear spike phenomenon may reflect economic factors, it is also possible that it reflects a form of measurement error induced by the calendar year nature of the data. Large investment projects that start late in one calendar year and completed in the subsequent year can easily yield this pattern. Results presented below provide further support for this interpretation.

On face value, these findings do not support the prediction of an upward sloping hazard and thus do not support the predictions of the machine replacement model. However, it is likely that these empirical hazards reflect a variety of forces beyond those we emphasize in the theoretical analysis. For example, as is well known in the empirical labor economics literature, unobserved structural heterogeneity can yield downward sloping hazards even if the hazard for any individual plant is upward sloping. Put differently, the empirical hazards depicted in Figure 10 reflect between plant and within plant effects while the prediction of an upward sloping hazard is a within plant prediction.

E. Estimating Hazards with Fixed Effects

To separate the competing influences on the empirical hazards, we estimate the following parsimonious specification: 


$$
h_{e t}=\alpha_{e}+\alpha_{t}+\sum_{k} \alpha_{k} D_{k e t}+\epsilon_{e t}
$$

where $h_{e t}=1(0)$ if plant e has (does not have) an investment spike in period $t, \alpha_{e}$ represents a plant fixed effect, $\alpha_{\mathfrak{t}}$ represents a common year effect, and $D_{\text {ket }}$ are investment age dummies. ${ }^{27}$ When the plant fixed effects and year effects are not included, this specification yields the Kaplan-Meir pooled sample estimates. The inclusion of the plant fixed effects is intended to absorb the between plant differences in the likelihood of having an investment spike so that the estimated coefficients on the investment age dummies can reflect the timing relationship among investment spikes within plants. Given that we include the fixed effects, we cannot interact the investment age effects with year effects and so must constrain the year effect to be the same across all investment age groups.

The year effects capture any factors that shift the hazard across time. In our formal model under the assumption of a time invariant distribution of independently distributed idiosyncratic shocks, the hazard shifts over time only due to aggregate shocks. However, other factors such as time variation in the distribution of idiosyncratic shocks can shift the hazard over time. Thus, it is appropriate to interpret the year effects as reflecting all factors that shift the hazard over time. Accordingly, in what follows we will refer to these time

\footnotetext{
27 This simple specification is motivated by a number of factors. First, it imposes no parametric functional form on the hazard. Second, this structure lends itself to the aggregate decomposition exercises considered in the next section. In spite of its simple appeal, there are a number of potential econometric concerns. First, to control for the fixed effects the model is estimated after subtracting plantspecific means from the dependent and independent variables. As discussed by Chamberlain [1991], this method using least squares is not subject to inconsistency due to the incidental parameters problem as long as there is sufficient within plant variation in the investment age variables. A potentially related problem is that the errors may be serially correlated. Identifying the within plant relationship between investment rates and investment ages is particularly problematic in the presence of serially correlated idiosyncratic shocks. The problem of distinguishing between state dependence and serially correlated errors is a well known and difficult problem. While we have not pursued this problem formally, we did try a solution suggested by the work of Olley and Pakes [1992] by including lagged plant-leve] employment as an additional explanatory variable in the estimation. The basic idea is that such a lagged endogenous variable could absorb the influence of serially correlated idiosyncratic shocks. Resuits from this exercise (not reported) yield very similar coefficients on the year and investment age effects to those reported here, although the estimated coefficient on lagged employment is positive and statistically significant.
} 
series shifts in the hazard as hazard shocks.

The results of estimating equation (8) are presented in Table $1 . .^{28}$ The coefficient estimates for $\alpha_{k}$ for selected years are depicted in Figure 11 with the intercept shifts across years reflecting the year effects. In interpreting Figure 11, note that the fixed effects have been absorbed so that the average $\alpha_{k}$ across the years has a mean of zero. For all spike definitions, the estimated hazards are $u$-shaped with respect to investment age. The probability of having an investment spike in the period immediately after an investment spike is still quite high even after controlling for fixed effects. However, using either the upper absolute spike or the relative spike definition, the probability drops substantially from investment age 0 to investment age 1 and then increases for each additional year since the previous investment spike. For example, for the high absolute spike definition, a plant with an investment age of 1 is $12 \%$ less likely to experience an investment spike than a plant of investment age 8 . The lower absolute spike definition also yields a u-shaped pattern but the trough is at investment age equal to 4 and the subsequent increase in the hazard is not monotonic.

For all specifications, the estimated age effects are highly statistically significant: i.e. we reject the flat hazard model. Further, we clearly reject the downward sloping hazard model. Only from age 0 to age 1 does the hazard decrease with age and this latter feature is potentially driven by the limitations of using calendar year data. In short, once we control for fixed effects, neither the random shock model implying a flat hazard or the convex adjustment cost model implying a downward sloping hazard are consistent with the estimated

\footnotetext{
2s Table 1 reports the coefficients for several intermediate specifications. That is, specifications with just year effects and specifications in which the fixed effects are at the industry rather than the plant level are reported.
} 
hazards. Instead, the estimated hazards are consistent with the predictions of the machine replacement model.

The shifts in the investment spike hazards across years depicted in Figure 11 reveal a strikingly procyclical pattern. From Figure 8, the years depicted represent a business cycle episode with high aggregate investment in 1981, substantially lower aggregate investment in 1982 and 1983 and high aggregate investment again in 1984 and 1985 . The estimated hazards follow this same pattern indicating that the probability of having an investment spike increases during periods of high economic activity. This provides support for the specification of the model that yields procyclical hazards -- specifically, sufficient serial correlation in the aggregate shocks and high fixed as opposed to proportional costs of replacement.

F. Aggregate Implications

Consider the following alternative decompositions values of actual investment:

$$
I_{t}=I_{t}^{g}+\left(I_{t}-I_{t}^{8}\right) \text { where } I_{t}^{8}=\sum_{k} h_{k m} g(k)
$$

and

$$
I_{t}=I_{t}^{k}+\left(I_{t}-I_{t}^{k}\right) \text { where } I_{t}^{k}=\sum_{k}\left[\left(\frac{1}{E}\right) \sum_{e} \alpha_{e}+\alpha_{k}\right] g_{t}(k)
$$

where $\mathrm{E}$ is the total number of plants, the $\alpha$ 's in equation (9) refer to the estimated coefficients from equation (8), $\mathrm{I}_{\mathrm{l}}$ is the aggregate fraction of plants having an investment spike (what we hereafter refer to as aggregate investment), $\mathrm{g}_{\mathrm{c}}(\mathrm{k})$ is the empirical investment 
age distribution, ${ }^{29}$ and $h_{\mathrm{kmt}}$ are the Kaplan-Meir hazard estimates (i.e., the empirical hazards).

The measure $\mathrm{I}_{r}^{8}$ characterizes the predicted behavior of aggregate investment using the actual empirical hazard (the Kaplan-Meir by year estimates) with the time series average of the cross sectional distribution $\mathrm{g}(\mathrm{k})$. Comparing the time series behavior of this measure to the actual fraction of plants having investment spikes provides a basis for evaluating the importance of time series fluctuations of the cross sectional age distribution. An important feature of this decomposition is that it does not rely on our ability to identify the separate influences on the empirical hazard. That is, the Kaplan-Meir by year estimates incorporate all of the forces (i.e., plant fixed effects, depreciation, obsolescence, aggregate shocks, idiosyncratic shocks) that yield fluctuations in investment patterns by investment age groups. Thus, this measure characterizes the predicted path of investment under the assumptions that all of these forces are at work but with a time invariant cross sectional age distribution.

The measure $I_{1}^{k}$ uses the actual cross sectional age distribution but abstracts from hazard shocks. Comparing the time series properties of this measure with aggregate investment provides a basis for evaluating the contribution of the interaction of the non-flat hazard with the cross sectional age distribution.

For the subsequent analysis of these decomposition exercises, we focus our attention on the results for the upper absolute spike definition. ${ }^{30}$ The time series of $\mathrm{I}_{1}^{\mathrm{k}}$ and $\mathrm{I}_{1}^{\mathrm{g}}$ are

\footnotetext{
29 Note that $k$ and thus $g(k)$ indexes the time since the last large investment episode not the vintage of the capital stock as in the theoretical model. However, as we pointed out in section III.A, there is a one-to-one mapping between the time since the last replacement and the vintage of the capital stock in the theoretical model.

30 Similar results are obtained using the other spike definitions.
} 
plotted against the actual fraction of plants experiencing investment spikes in Figure $12 .{ }^{31}$ $\mathrm{I}_{1}^{\mathrm{g}}$ tracks aggregate investment quite closely implying that time series variation in the cross sectional age distribution has only a modest marginal contribution -- or put conversely, fluctuations in the hazard are what matter most. In terms of measures of goodness of fit, the root mean squared error associated with $I_{t}^{8}$ (i.e., the difference between $I_{t}$ and $I_{t}^{B}$ ) is 0.004 . These are small forecast errors relative to the variation exhibited by aggregate investment (standard error of the latter is 0.021 ).

The flip side of these results is that the series $I_{1}{ }^{k}$ exhibits only modest movements over time. However, close examination makes it clear that during periods of the greatest movement in $I_{t}^{k}$ there are some interesting and important differences between $I_{t}$ and $I_{l}^{g}$. Specifically, in periods in which $\mathrm{I}_{1}^{\mathrm{k}}$ is relatively low (high) are precisely those periods that $\mathrm{I}_{\mathrm{l}}^{\mathrm{g}}$ overpredicts (underpredicts) the actual increase in $\mathrm{I}_{t}$. Consider, for example, the years 198487. In 1984 , the non-flat hazard interacting with the cross sectional distribution yields a relatively low $\mathrm{I}_{\mathfrak{}}^{\mathrm{k}}$. Ignoring this interaction (as $\mathrm{I}_{\mathrm{b}}^{\mathrm{g}}$ does) yields an overprediction of actual investment. In the succeeding years 1985 and 1986, the interaction of the non-flat hazard and the cross sectional age distribution yields a positive increase to aggregate investment and ignoring this yields an underprediction of actual investment. In 1987, the interaction of the non-flat hazard and the cross sectional age distribution yields a negative contribution to the change in investment and thus ignoring this component yields an overprediction of investment.

This pattern of overprediction and underprediction is precisely what one would expect

\footnotetext{
3 In generating the series for Figure 12, we standardized all of the series to have the mean of the actual investment series. That is. we eliminated any mean differences between the series.
} 
if the machine replacement model was correct but the implied influence of the cross sectional age distribution was ignored. Recall from the time series simulation that the influence of the cross sectional age distribution is twofold. First, the impact of aggregate shocks depends on the state of the cross sectional age distribution. Second, endogenous cycles in investment emerge when the existing cross sectional age distribution differs sharply from that associated with the steady state distribution consistent with current aggregate conditions. Both of these effects are especially important in the periods immediately following large fluctuations in aggregate investment. Further, while both of these effects lead to prediction errors, it is this latter effect that generates a pattern of over and under prediction when one ignores the influence of the cross sectional age distribution and the non-flat hazard.

Viewed from this perspective, it is useful to focus on episodes following sharp swings in aggregate investment. Figure 13 shows that the associated prediction errors for the change in investment are non-trivial in periods following large fluctuations in aggregate investment. Figure 13 depicts the actual changes in investment spikes (right vertical axis) against the fraction of the actual change accounted for by the predictions from alternative decompositions. In 1985, $\mathrm{I}_{1}^{\mathrm{g}}$ accounts for about $40 \%$ of the increase in investment. In 1987, $I_{1}^{8}$ accounts for about $230 \%$ of the increase in investment.

Observe that after the large hazard shocks in the 1983-85 period, hazard shocks are relatively small in magnitude in the period 1986-90. Accordingly, the impact of the interaction of the cross sectional age distribution and the non-flat hazard diminished over this period of time. Based upon the very sharp decline in investment in 1991 (the end of our sample) generated by a large adverse hazard shock, we would predict relatively large 
prediction errors from ignoring the interaction of the cross sectional age distribution and the non-flat hazard in the immediately following years.

How do we reconcile the somewhat conflicting implications of Figures 12 and 13 ? The key is to recognize that the interaction of the cross sectional age distribution and the non-flat hazard generates endogenous cycles in investment. Thus, ignoring these factors will not yield large prediction errors in the levels but can lead to larger, systematic prediction errors in the changes, particularly in periods in which the cross sectional age distribution has been substantially disrupted.

Interestingly, conducting a dynamic simulation of the cross sectional age distribution based upon our estimated hazard yields an aggregate investment series that closely tracks the actual changes in aggregate investment. The series labeled "Dynamic" in Figure 13 shows that the prediction error of the dynamic simulation is small in magnitude in all periods, including periods of large investment fluctuations. Thus, using our estimated model that incorporates the impact of the investment age distribution performs quite well in predicting investment changes relative to the predictions based on neglecting the impact of the cross sectional distribution.

\section{Conclusion}

Our goal in this paper was to model the machine replacement problem of an individual producer and then to trace the implications of this discrete choice problem for the behavior of aggregate investment. To do so, we analyzed the choice of an individual agent with emphasis on the timing of replacement relative to the business cycle. Here we found that replacement investment is more likely to be procyclical the more persistent are shocks 
and the more important are fixed adjustment costs. Further, the theoretical model predicted fairly rich dynamics in aggregate investment due to the interaction of the aggregate shocks and the tendency of the cross sectional distribution of capital vintages to evolve to its stationary distribution.

The empirical section of the paper provides evidence that these theoretical properties are apparent in the data. First, large investment episodes are an important feature of plant level investment and constitute a large fraction of aggregate fluctuations in investment. Second, estimates of microeconomic hazards reveal that once fixed effects have been taken into account, the probability of a large investment episode (denoted an investment spike) is increasing in the time since the previous spike. Third, the investment spike hazards are procyclical. Putting these pieces together implies that ignoring fluctuations in the cross sectional distribution of the vintage of the capital stock can lead to non-trivial errors in the predicted changes in the fraction of plants experiencing investment spikes. Strikingly, the relative importance of the prediction errors increases during periods of large investment fluctuations.

There are at least three directions in which to build upon our work. First, the model excludes any movements on the intensive margin by assuming that all investment projects are of the same size. While analytically convenient, the empirical implementation of this approach requires the creation of a discrete variable from observations on investment flows. An alternative approach, which we will pursue, is to build a richer model of investment which allows the agent to choose a path of investment with nonconvex costs of adjustment. This may also include a description of the effects of capital market imperfections. This 
model will be easier to implement empirically and will nest the standard neoclassical model of investment as a special case.

Second, working from the fundamental contribution of Rust [1987] and others, there is an alternative empirical strategy to pursue: the estimation of the structural model from the LRD. While our empirical work did not require the imposition of a particular hazard function, the approach does not provide a link between the estimates and the underlying structural model. In future work, we will make this link explicit and provide microeconomic estimates of an investment model with nonconvex costs of adjustment.

The final issue concerns the links between capital, worker flows and productivity. This paper concentrates on the timing of large investment episodes while others, e.g. Davis and Haltiwanger [1992] focus on employment movements. An integrated model of investment activity and labor market dynamics with implications for productivity is an obvious next step. 


\section{$\underline{\text { References }}$}

Abel, A. "Consumption and Investment," Chpt. 14 in Handbook of Monetary Economics, ed. by B.M. Friedman and F.H. Hahn, Elsevier Science Publishers, 1990

Abel, A. and J. Eberly, "A Unified Model of Investment Under Uncertainty," American Economic Review, 94 (1994), 1369-84.

Bernanke, B., M. Gertler and S. Gilchrist, "The Financial Accelerator and the Flight to Quality," mimeo, October 1993.

Bertola, G. and R. Caballero, "Kinked Adjustment Costs and Aggregate Dynamics," NBER Macroeconomics Annual, (1990), 237-87.

Caballero, R. and E. Engel, "Dynamics (S,s) Economies" Econometrica, 59 (1991), 165986.

"Microeconomic Adjustment Hazards and Aggregate Dynamics," Quarterly Journal of Economics, 108 (1993a), 359-84.

,"Explaining Investment Dynamics in U.S. Manufacturing: A

Generalized (S,s) Approach", mimeo, December 1993b. and J. Haltiwanger, "Aggregate Employment Dynamics: Building from Microeconomic Evidence", NBER Working Paper No. 5042, February 1995a. and J. Haltiwanger, "Plant Level Adjustment and Aggregate Investment Dynamics", presented at the September 1995 Brookings Panel on Economic Activity, mimeo, August 1995b.

Cechetti, S., "The Frequency of Price Adjustment: A Study of the Newsstand Prices of Magazines, " Journal of Econometrics, 31 (1986), 255-274.

Chamberlain, G., "Analysis of Covariance with Qualitative Data, " Review of Economic Studies, 47 (1980), 225-238.

Chamberlain, G., "Panel Data, " in Handbook of Econometrics, Volume II, NorthHolland: Amsterdam, 1991.

Cooley, T., J. Greenwood, and M. Yorukglu, "The Replacement Problem," mimeo, November 1994. 
Cooper, R. and J. Haltiwanger, "Macroeconomic Implications of Production Bunching: Factor Demand Linkages, " Journal of Monetary Economics, 30 (1992), 107-28.

, "The Macroeconomic Implications of Machine Replacement:

Theory and Evidence," American Economic Review, 83 (1993),360-82 .

Davis, S. and J. Haltiwanger, "Gross Job Creation, Gross Job Destruction and Employment Reallocation," Quarterly Journal of Economics, 107 (1992), 819-63.

Doms, M. and T. Dunne, "Capital Adjustment Patterns in Manufacturing Plants, " mimeo, Center for Economic Studies, Census Bureau, 1993.

Gross, David, "The Investment and Financing Decisions of Liquidity Constrained Firms,", mimeo, November 1994.

Hamermesh, D. "Labor Demand and the Structure of Adjustment Costs, " American Economic Review, 79 (1989), 674-89.

Jovanovic, B. "Selection and the Evolution of Industry, " Econometrica, 50 (1982), 649-70.

Kiefer, N. "Economic Duration Data and Hazard Functions," Journal of Economic Literature, 26 (1988), 646-679.

King, R., C. Plosser and S. Rebelo, "Production, Growth and Business Cycles:I. The Basic Neoclassical Model," Journal of Monetary Economics, 21 (1988), 195-232.

Olley, S. and A. Pakes, "The Dynamics of Productivity in the Telecomunications Equipment Industry," Center for Economic Studies Working Paper No. 92-2, 1992.

Power, L. "Causes and Consequences of Investment Spikes in U.S. Manufacturing Plants," Ph.D. Thesis, University of Maryland, 1994.

Rothschild, M. "On the Costs of Adjustment, " Quarterly Journal of Economics, 85 (1971), 605-22.

Rust, J. "Optimal Replacement of GMC Bus Engines: An Empirical Model of Harold Zurcher, " Econometrica, 55 (1987), 999-1034.

Stokey, N. and R. Lucas, Recursive Methods in Economic Dynamics, Harvard University Press:Cambridge, MA. 1989. 
Appendix: Proofs

\section{Proof of Proposition 1}

As long as $\mu$ is small enough that $\beta<1$, then the existence of a solution to (7) is guaranteed by Theorem 9.6 in Stokey-Lucas [1989].

Proof of Proposition 2 Let A denote the productivity at the plant ignoring, for now, the decomposition of $A$. For a given value of $A$, let $k^{*}(A)$ satisfy $V^{n}(k, A)=V^{r}(k, A)$ where

$$
V^{n}(k, A) \equiv u(A k)+\beta E V\left(\rho k, A^{\prime}\right)
$$

and

$$
V^{r}(k, A) \equiv u(A k \lambda-F)+\beta E V\left(1, A^{\prime}\right)
$$

Letting $\Delta(k, A) \equiv V^{r}(k, A)-V^{n}(k, A)$, it is sufficient to show that $\Delta(k, A)$ is decreasing in $k$.

From (A1) and (A2),

$$
\Delta(k, A)=u(A k \lambda-F)-u(A k)+\beta E_{A^{\prime}}\left[V\left(1, A^{\prime}\right)-V\left(\rho k, A^{\prime}\right)\right]
$$

where $\mathrm{V}(\mathrm{k}, \mathrm{A}) \equiv \max \left\{\mathrm{V}^{\prime}(\mathrm{k}, \mathrm{A}), \mathrm{V}^{\mathrm{n}}(\mathrm{k}, \mathrm{A})\right\}$. Clearly the last part of this expression, representing the expected gains to replacement, is decreasing as $k$ increases since $V(k, A)$ is an increasing function of $k$. The first two terms capture the cost of replacement. If this cost is also increasing is $\mathrm{k}$, then $\Delta(\mathrm{k}, \mathrm{A})$ will be falling in $\mathrm{k}$. Differentiating the first two terms with respect to $\mathrm{k}$ yields

$$
A\left[\lambda u^{\prime}(A \lambda k-F)-u^{\prime}(A k)\right]
$$

In the event that $F=0$, this derivative is negative if $R(c)=-u^{\prime \prime}(c) / u^{\prime}(c)<1$ for all values of consumption. Thus, if the curvature of $u(\cdot)$ is not too large and $F=0$, then $H(k, A)$ is decreasing in $\mathrm{k}$. By continuity, this holds for $\mathrm{F}$ small.

If $u(\cdot)$ is linear, then $u(A \lambda k-F)-u(A k)$ will clearly be a decreasing function of $k$ for any value of $F$. This is also true for $u(\cdot)$ nearly linear.

This proves that given the state, the hazard is decreasing in $\mathbf{k}$. Since it is true for each realized value of $\mathrm{A}$, it is also true if one integrates over the idiosyncratic components of the shock to obtain the hazard defined over the aggregate state.

\section{Proof of Proposition 3}

Using the definition of $\Delta(k, A)$, for the case of $F>0$ and $\lambda=1$, we have 


$$
\Delta(k, A)=u(A k-F)-u(A k)+\beta E[V(1, A)-V(\rho k, A)]
$$

Since $A$ is iid the last term is independent of the current realization of the shock while the different in current utility flows, while negative, is an increasing function of $A$ due to the curvature of $u(\cdot)$.

\section{Proof of Proposition 4}

Again, using $\Delta(k, A)$ as defined above, we have:

$$
\Delta(k, A) \equiv u(A k \lambda)-u(A k)+\beta\left[E V\left(1, A^{\prime}\right)-E V\left(\rho k, A^{\prime}\right)\right]
$$

where the expectation is taken over $A^{\prime}$. Since $A$ is assumed to be iid, this expectation in independent of $\mathrm{A}$.

To show that replacement is less likely when $A$ is high, we need to show that $\Delta(k, A)$ is a decreasing function of $A$. With $A$ iid, this amounts to showing that $u(A k \lambda)-u(A k)$ is a decreasing function of $A$; i.e. the costs of replacement rise in good times due to the opportunity cost aspect of the replacement process. Differentiating this difference with respect to $A$ leaves the condition that $k\left[\lambda u^{\prime}(A k \lambda)-u^{\prime}(A k)\right]$ must be negative if $\Delta(k, A)$ is to fall with $A$. This last inequality is true iff $u(\cdot)$ is not too concave: i.e. iff $R(c) \leq 1$ for all $c$, where $R(c) \equiv-u^{\prime \prime}(c) / u^{\prime}(c)$.

\section{Proof of Proposition 5}

For the case of $F>0, \lambda=1$ and $u(\cdot)$ linear, $\Delta(k, A)$ is given by

$$
\Delta(k, A)=\beta E_{A^{\prime} \mid \mathrm{k}}\left[V\left(1, A^{\jmath}\right)-V\left(\rho k, A^{\prime}\right)\right]-F
$$

Note that the expectation over $A^{\prime}$ is conditional on A so that the current state of productivity does influence the replacement choice even though $\lambda=1$ and $u(\cdot)$ is linear. Since high values of $A$ put, by supposition, more weight on high values of $A^{\prime}$, it is sufficient to show that $V(1, A)-V(k, A)$ is increasing in $A$ for any $k$. This is, in turn, equivalent to the condition that

$$
\int_{k}^{1} V_{k A}(z, A) d z>0 .
$$

for all $k$. This condition is satisfied if $V_{k A}(k, A)>0$ for all $(k, A)$. From (A1) and (A2) this positive cross partial condition holds when $F>0, \lambda=1$ and $u(\cdot)$ is linear. To see this, note that by assumption, replacement will eventually occur so that $(A 1)$ is a sequence of current period returns with positive cross partials between $k$ and $A$. From (A2), $V^{\top}(k, A)$ has a positive cross partial since the second term is independent of $\mathbf{k}$. 
Table 1

Coefficients from the Regression of Spike and Age

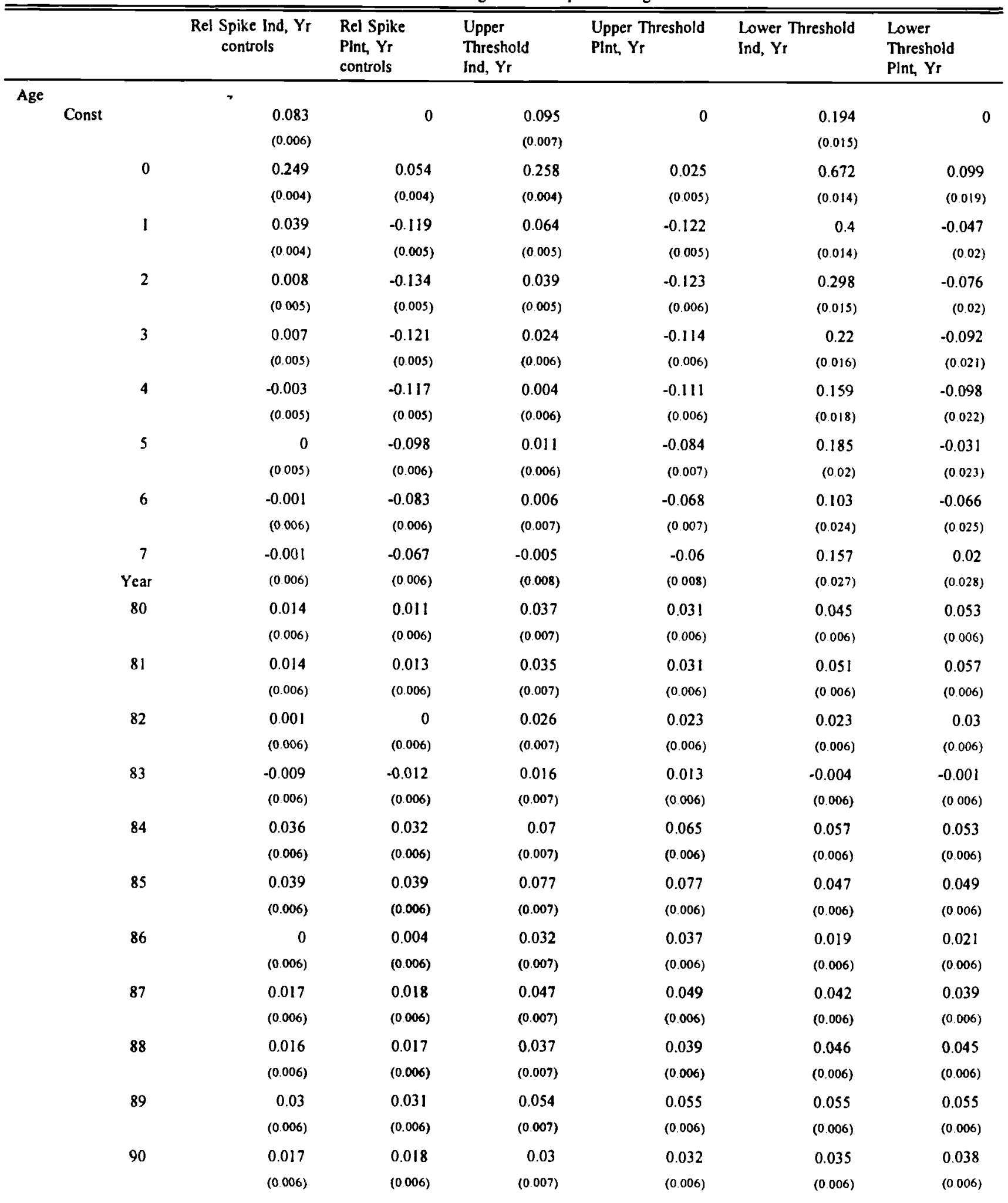


F test for Age

0.001

0.001

0.001

0.001

0.001

0.001

F test for Year

0.001

0.001

0.001

0001

000

0.001 
Figure 1

\section{Hazard Function}

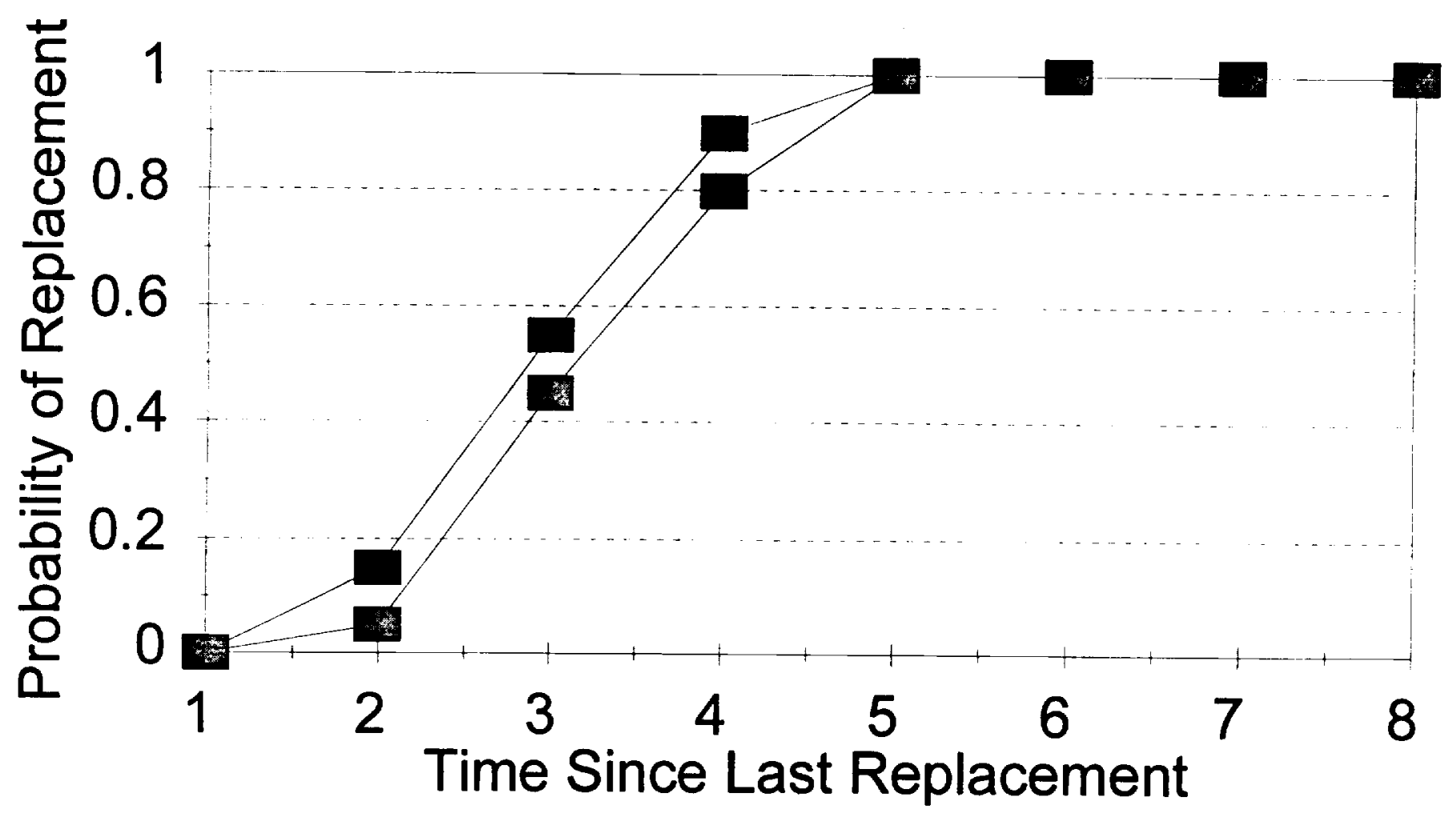

High State Low State 


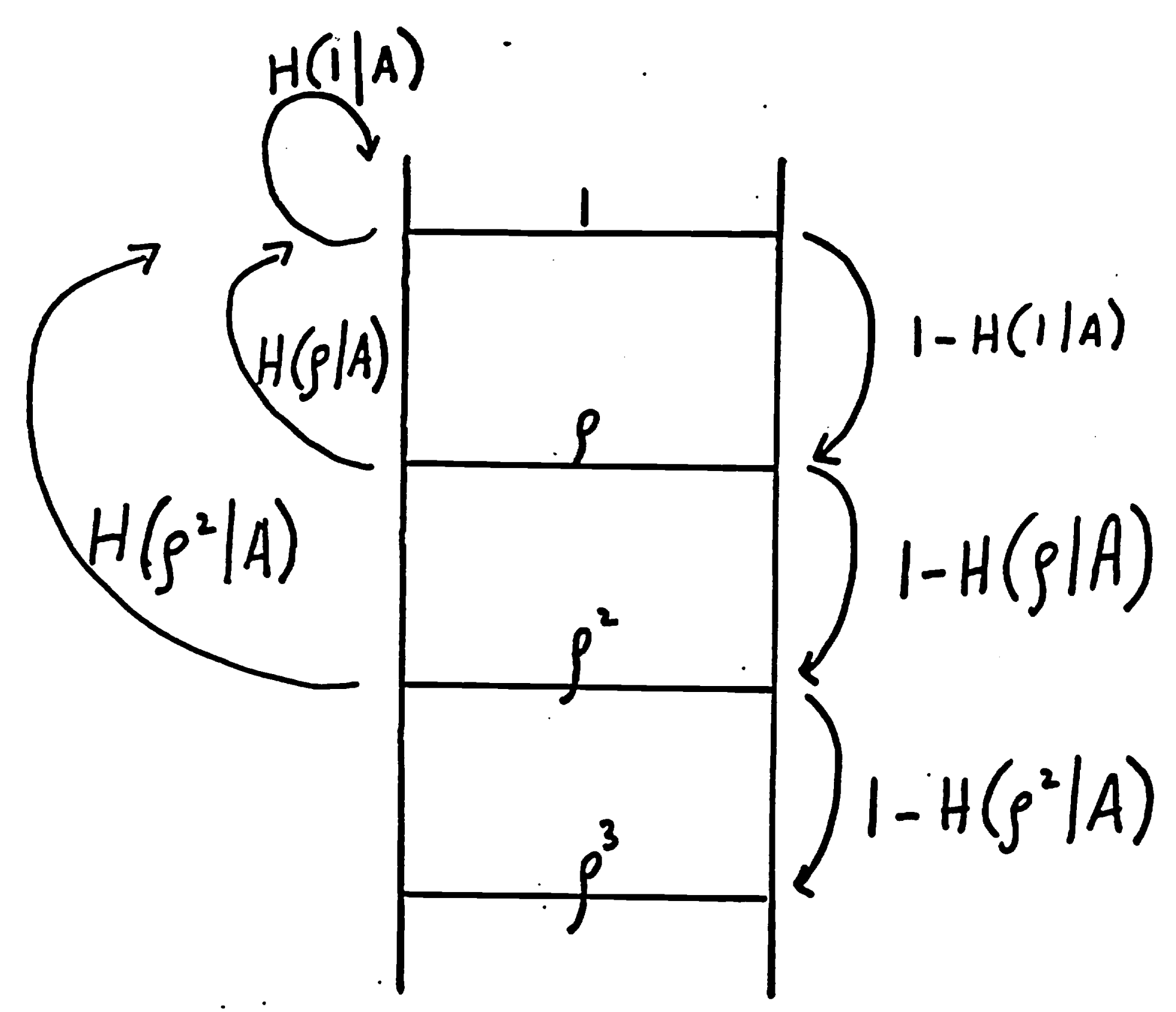

FIGURE 2 
Figure 3

\section{Convergence without Agg. Shocks Baseline Parameters}

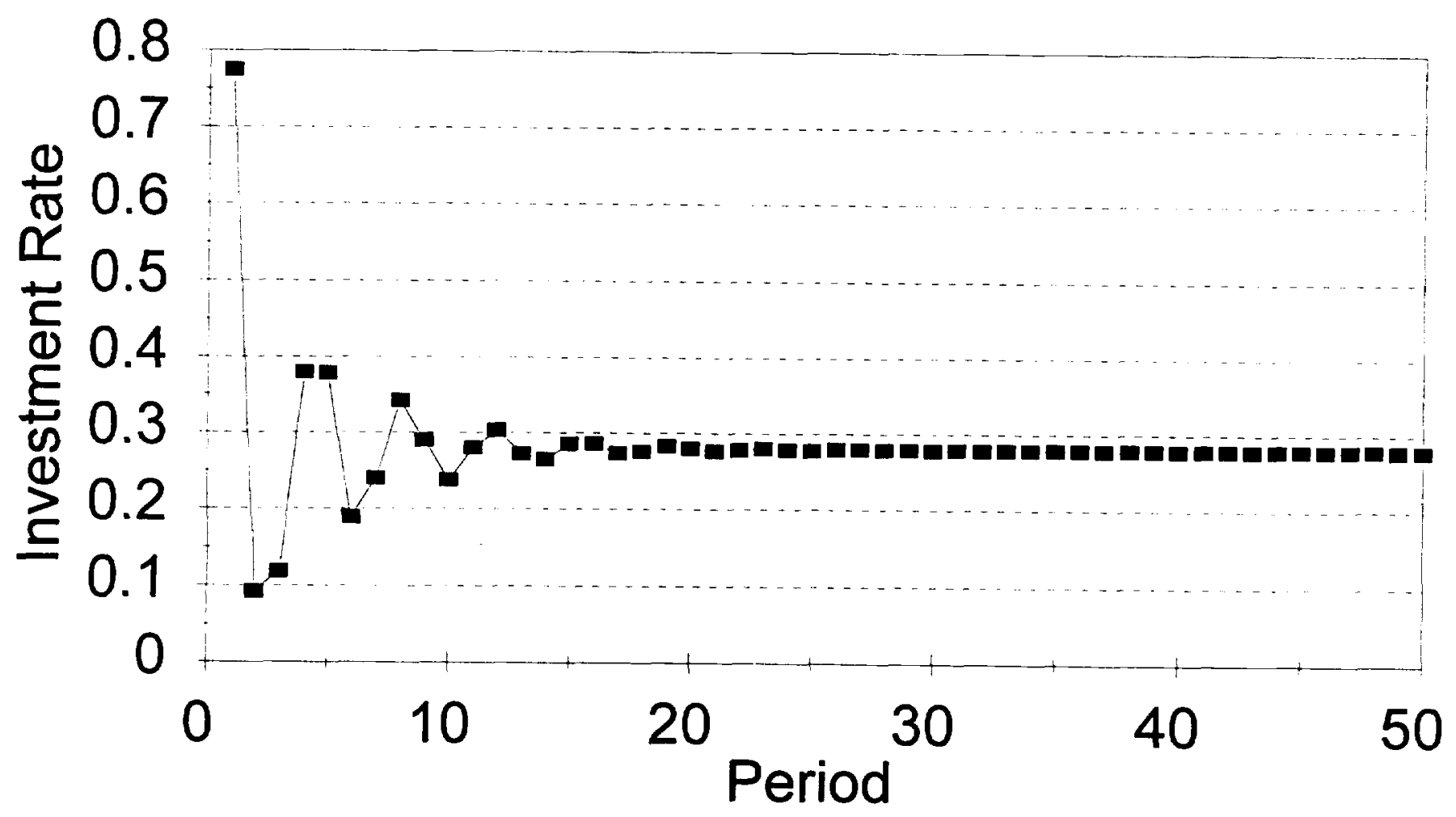




\section{Aggregate Investment Fluctuations Baseline Simulation}

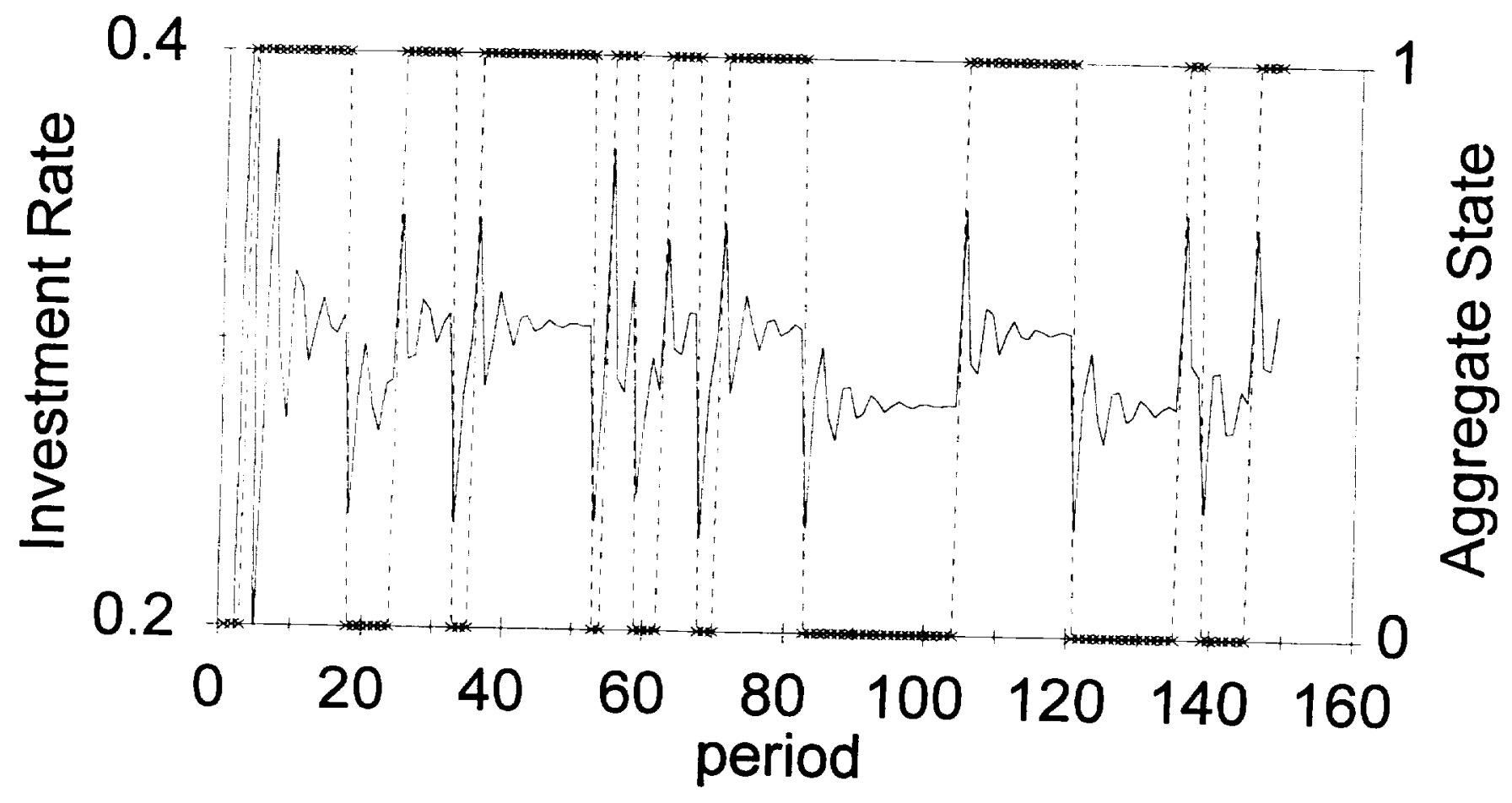

- Investment Rate * Aggregate State 


\section{Equlpment Investment In Manufacturing}

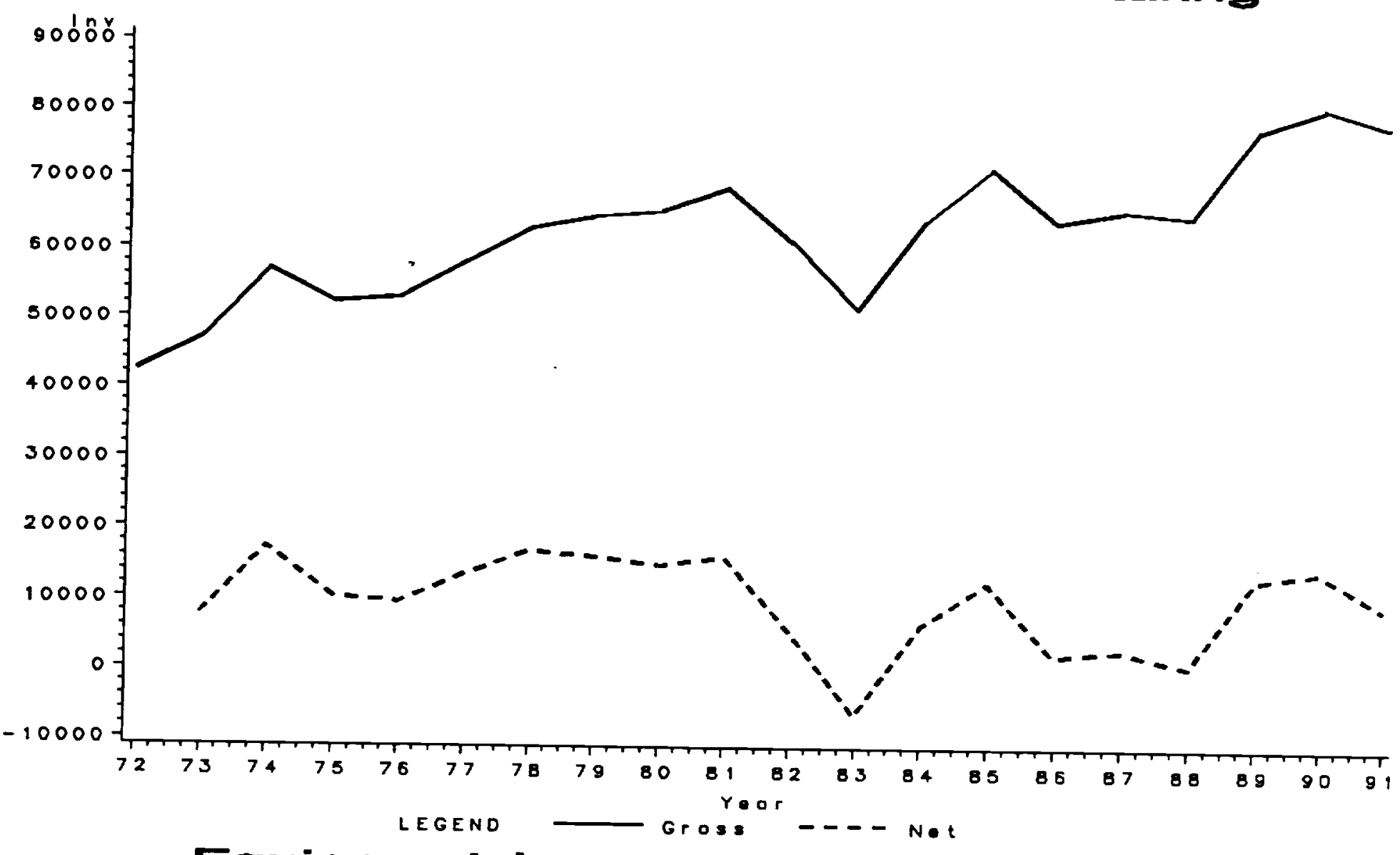

\section{Equipment Investment of Continuers}

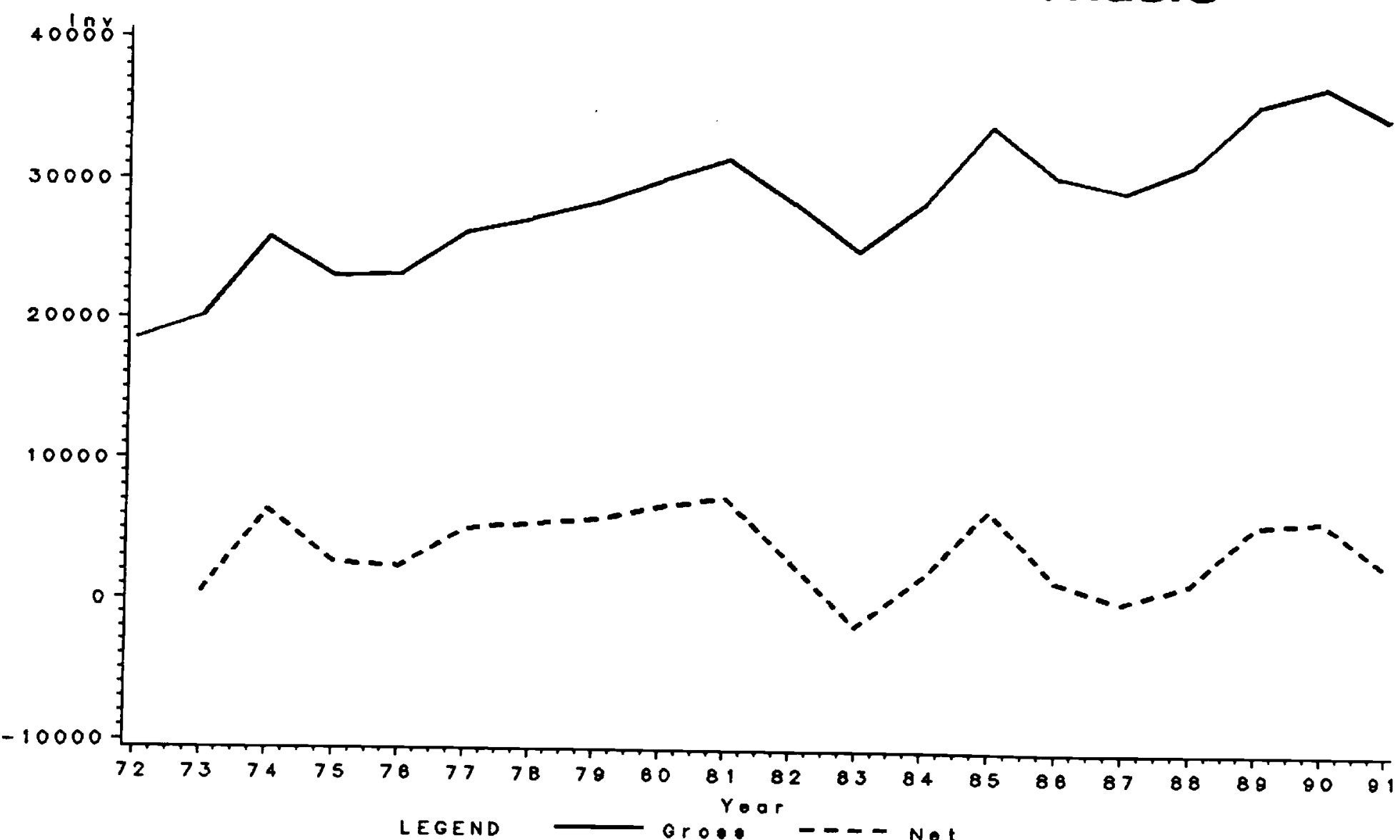




\section{Plant Level Investment Distribution}

Percent of Plants

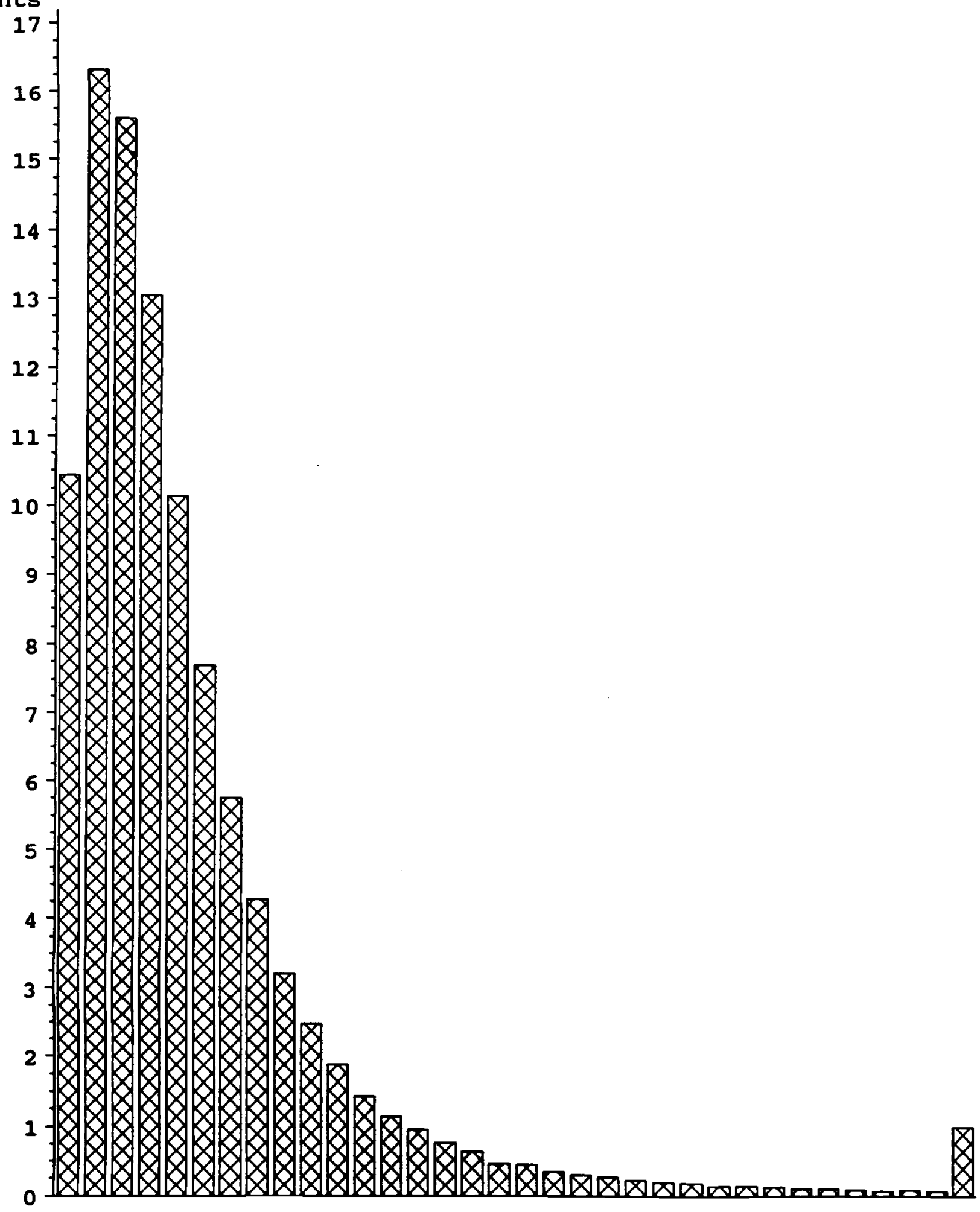

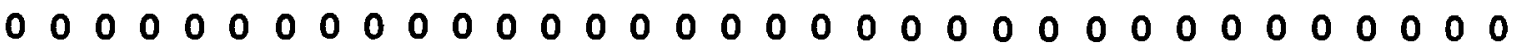

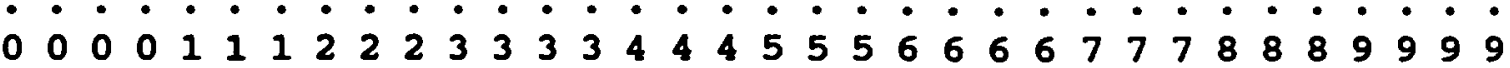

$\begin{array}{llllllllllllllllllllllllllllllllll}0 & 3 & 6 & 9 & 2 & 5 & 8 & 1 & 4 & 7 & 0 & 3 & 6 & 9 & 2 & 5 & 8 & 1 & 4 & 7 & 0 & 3 & 6 & 9 & 2 & 5 & 8 & 1 & 4 & 7 & 0 & 3 & 6 & 9\end{array}$ Distribution of Plant Level Investment 
Figure 7

\section{Contribution of Ranked Annual Investment to Cumulative}

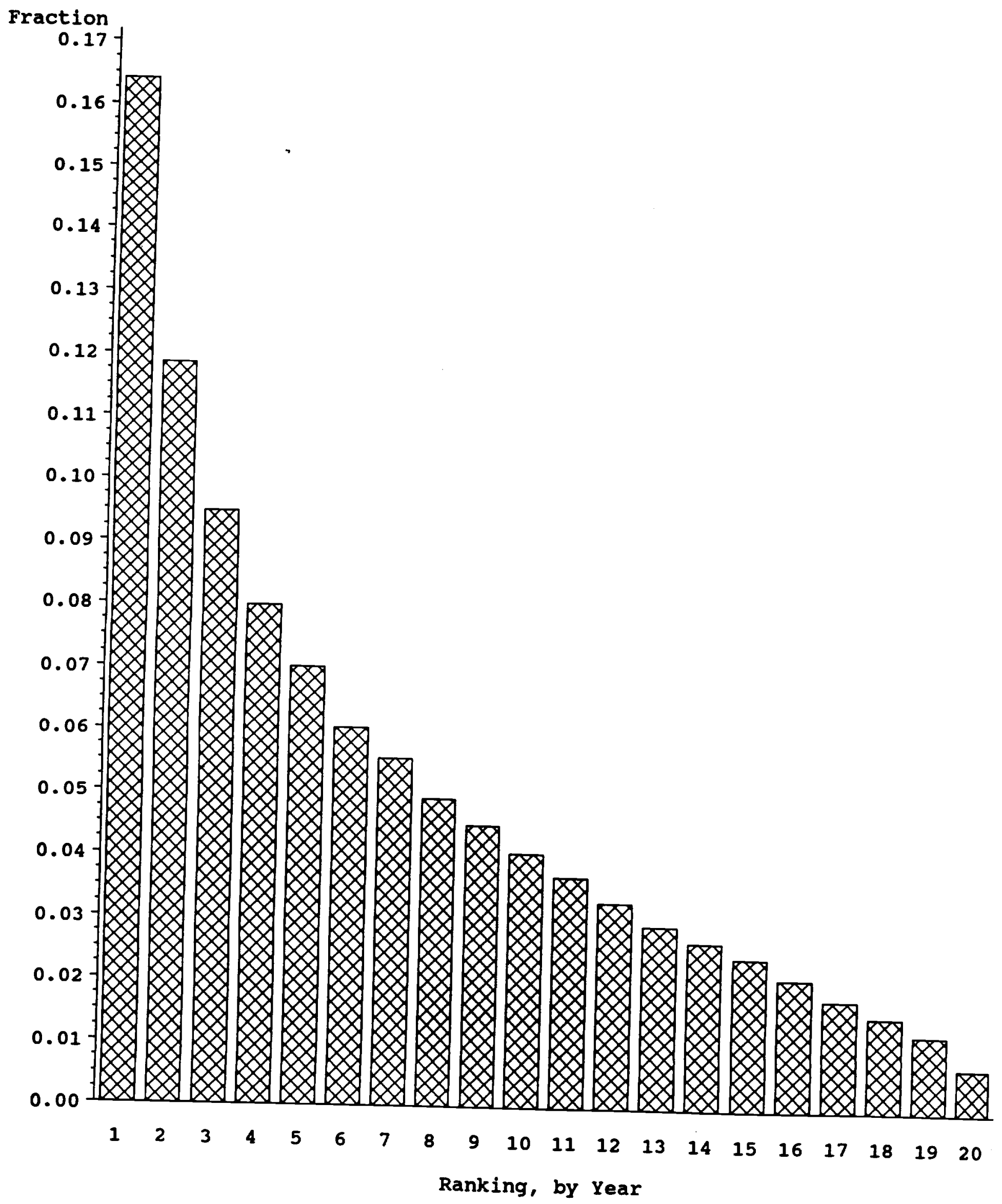




\section{Investment Rate vs Investment Spikes}

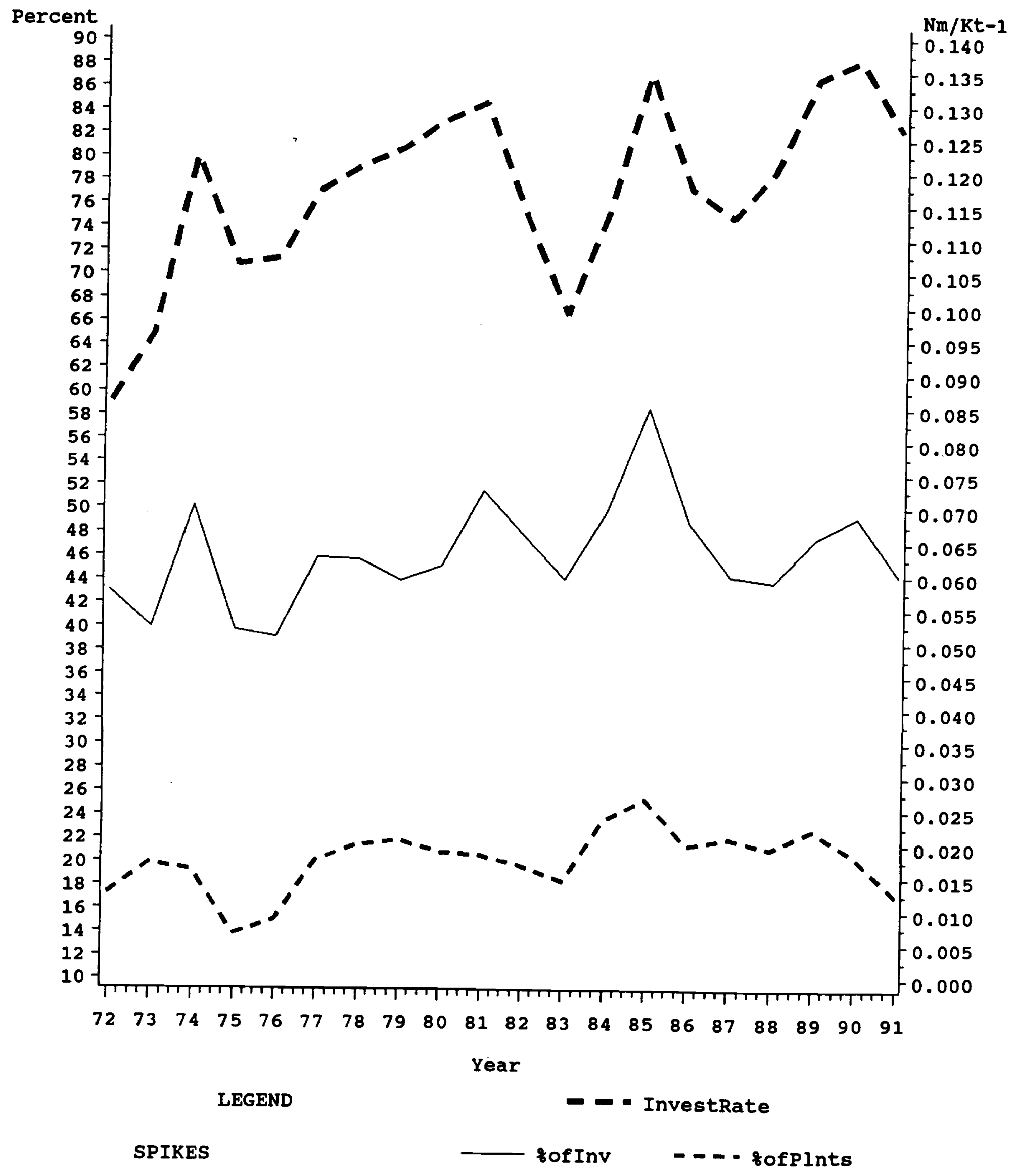


Figure 9

\section{investment rates}

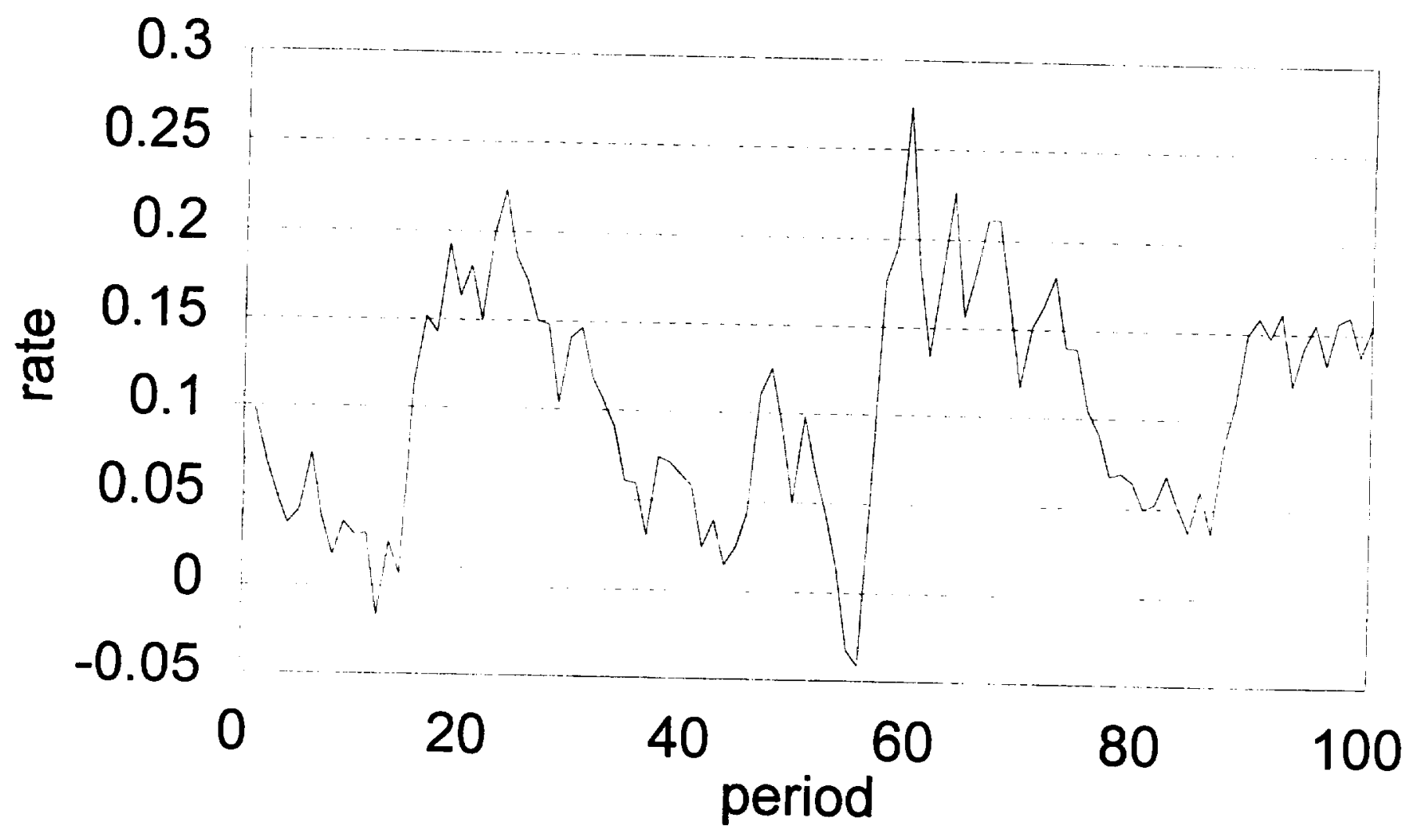




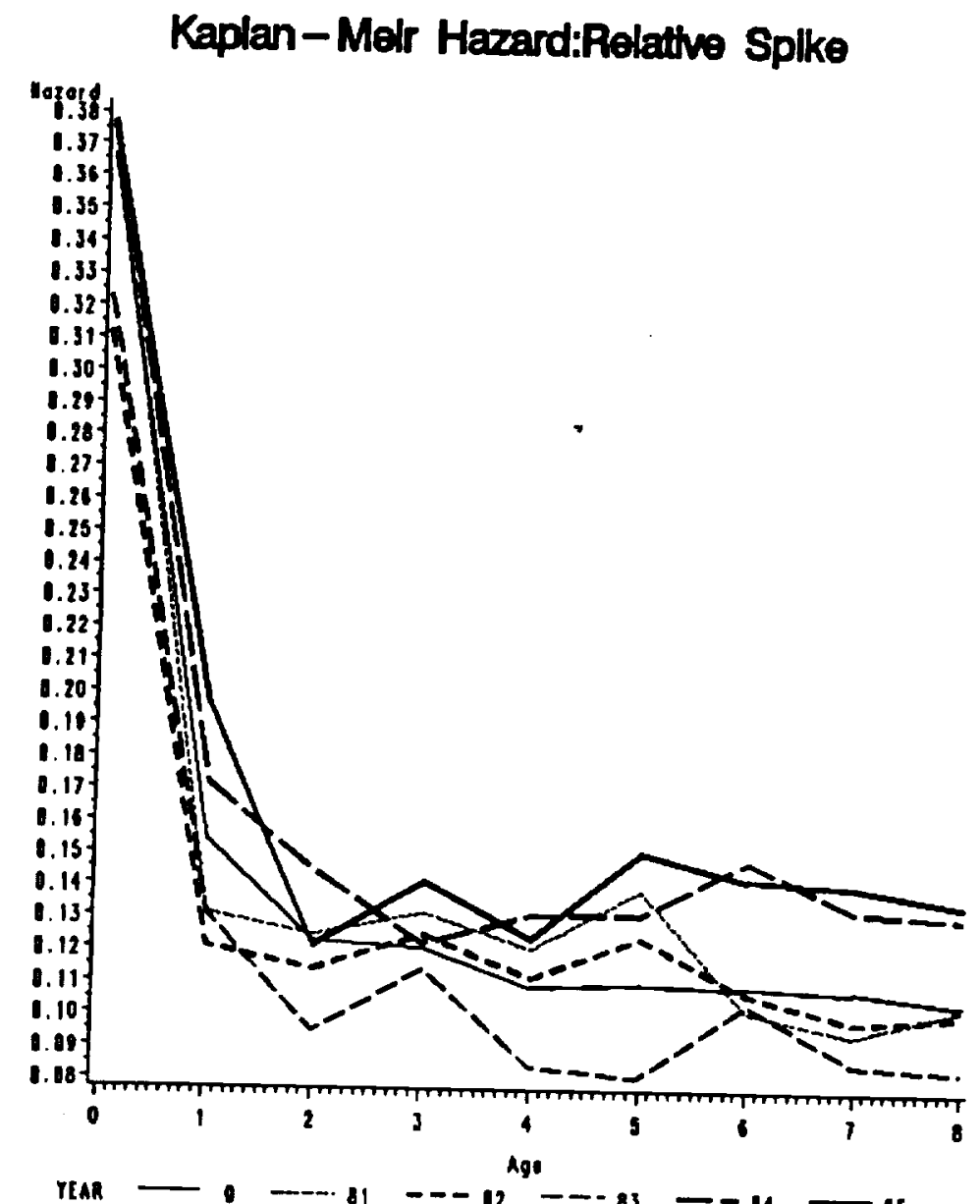

Kaplan-Melr Hazard:Relattve Splke

Kaplan-Melr Hazand:Lower Aboolute Splke

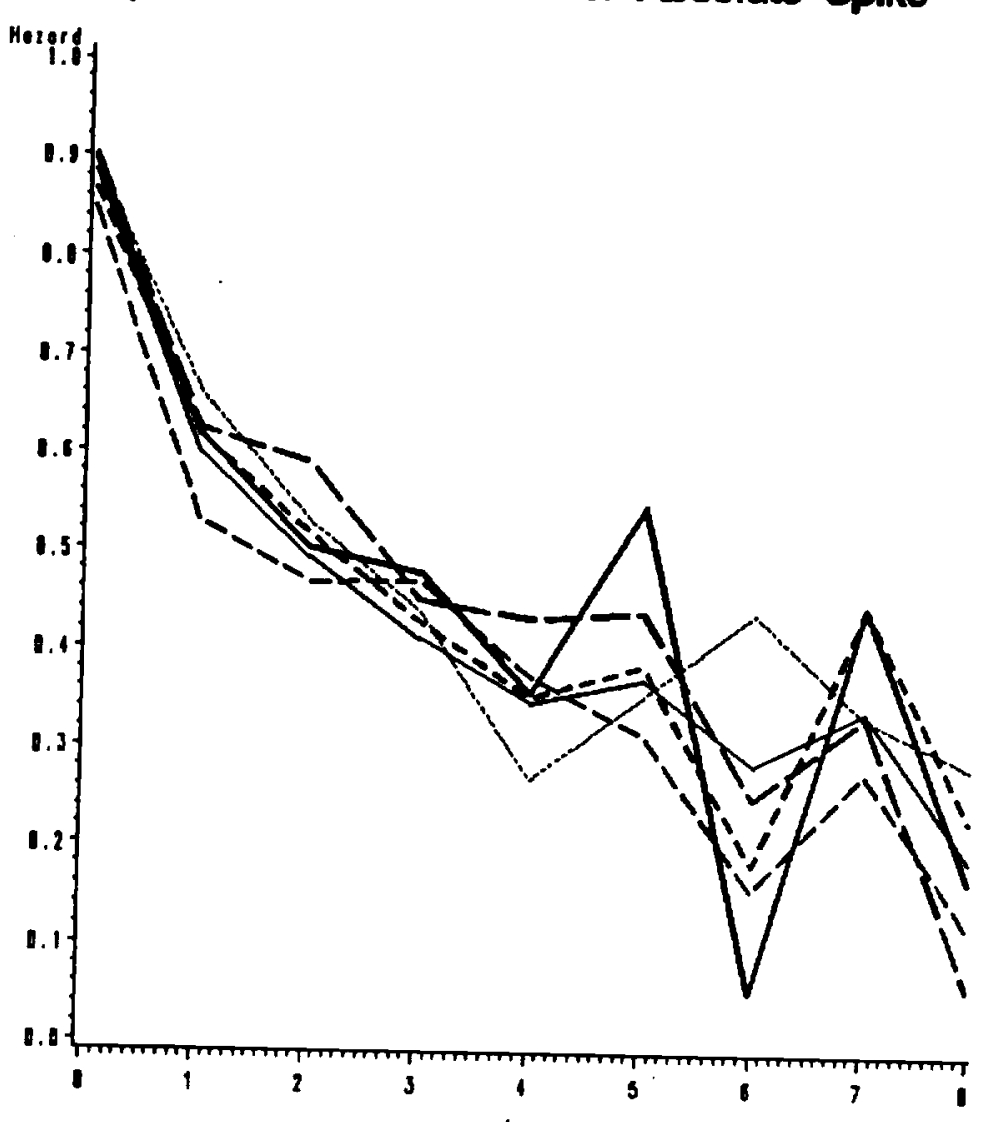

\section{Kaplan-Meir Hazard:Upper Absolute Spike}

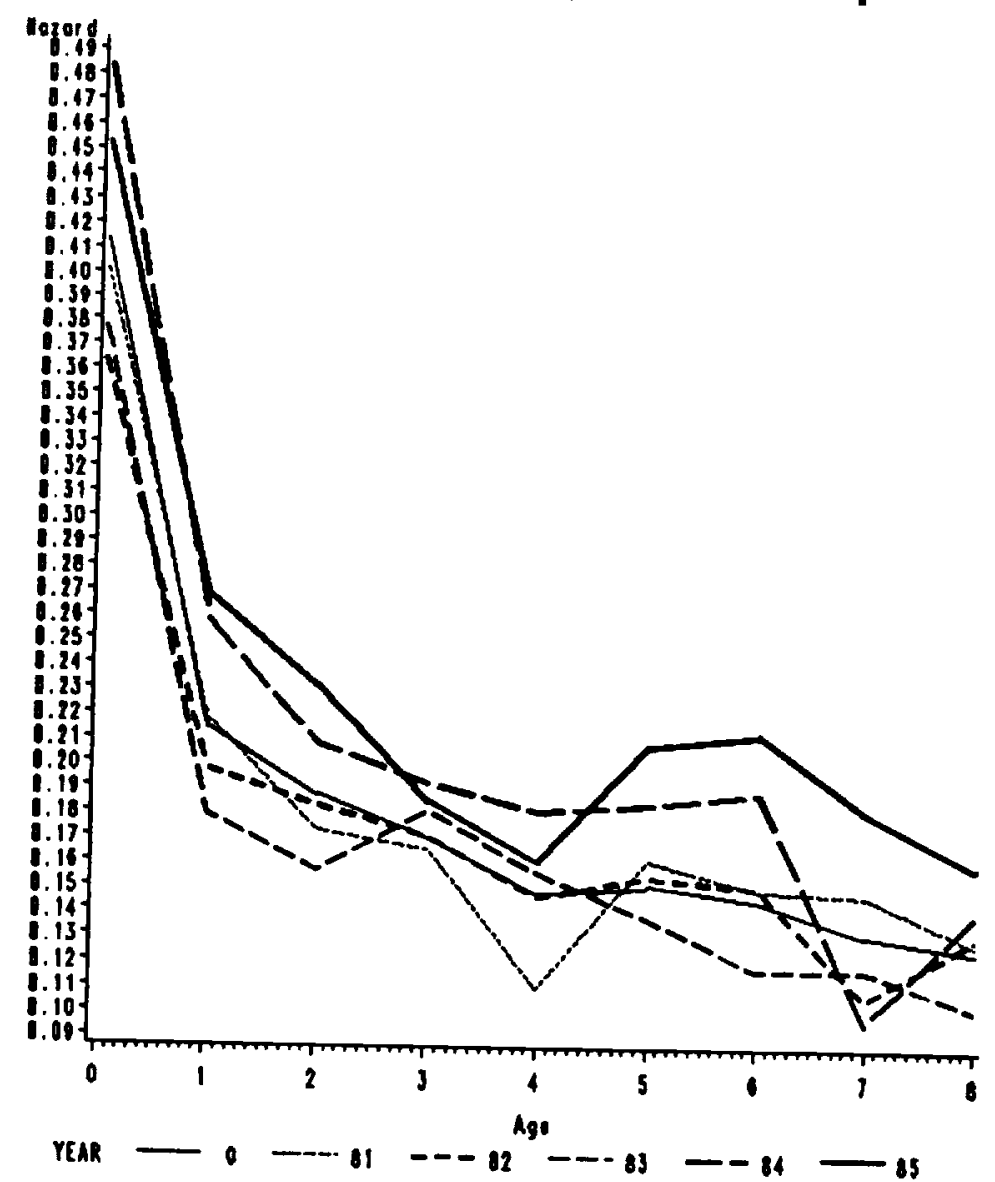


Hazand, wth Fixed Effects: Relattve Splke

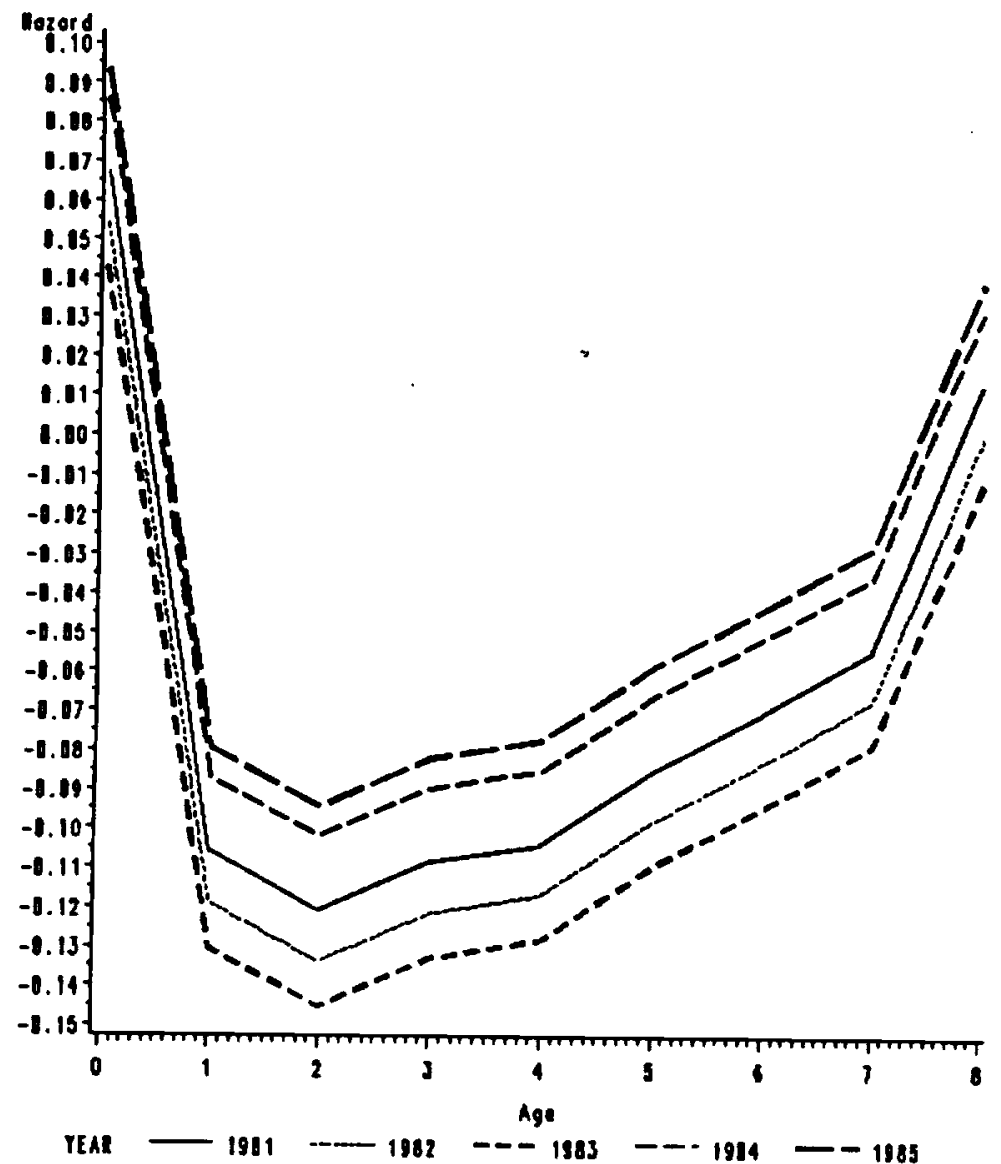

Hazard, with Fixed Effects: Upper Absoluto Spike

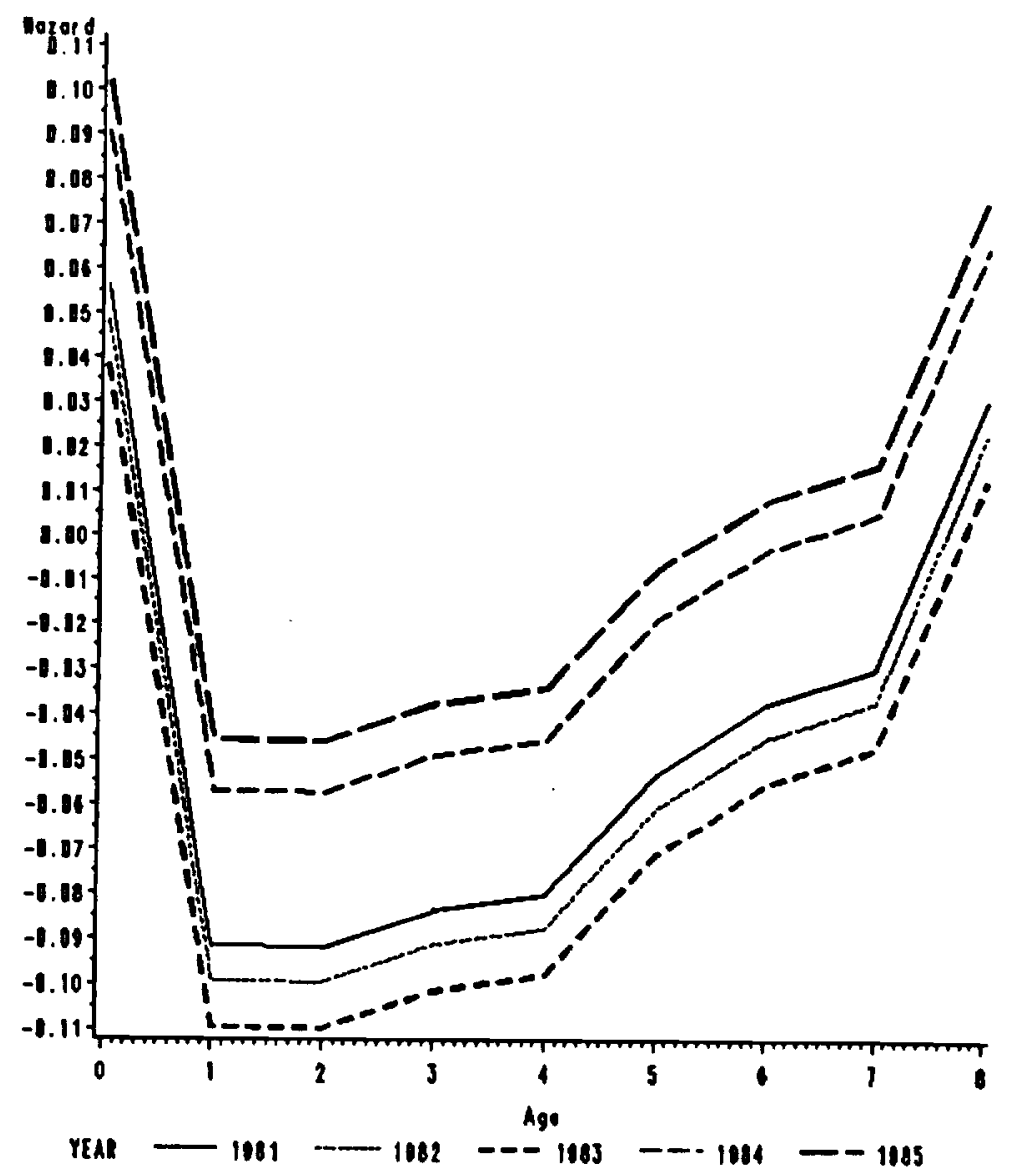

Hazard, with Flxed Effects: Lower Absolute Splke

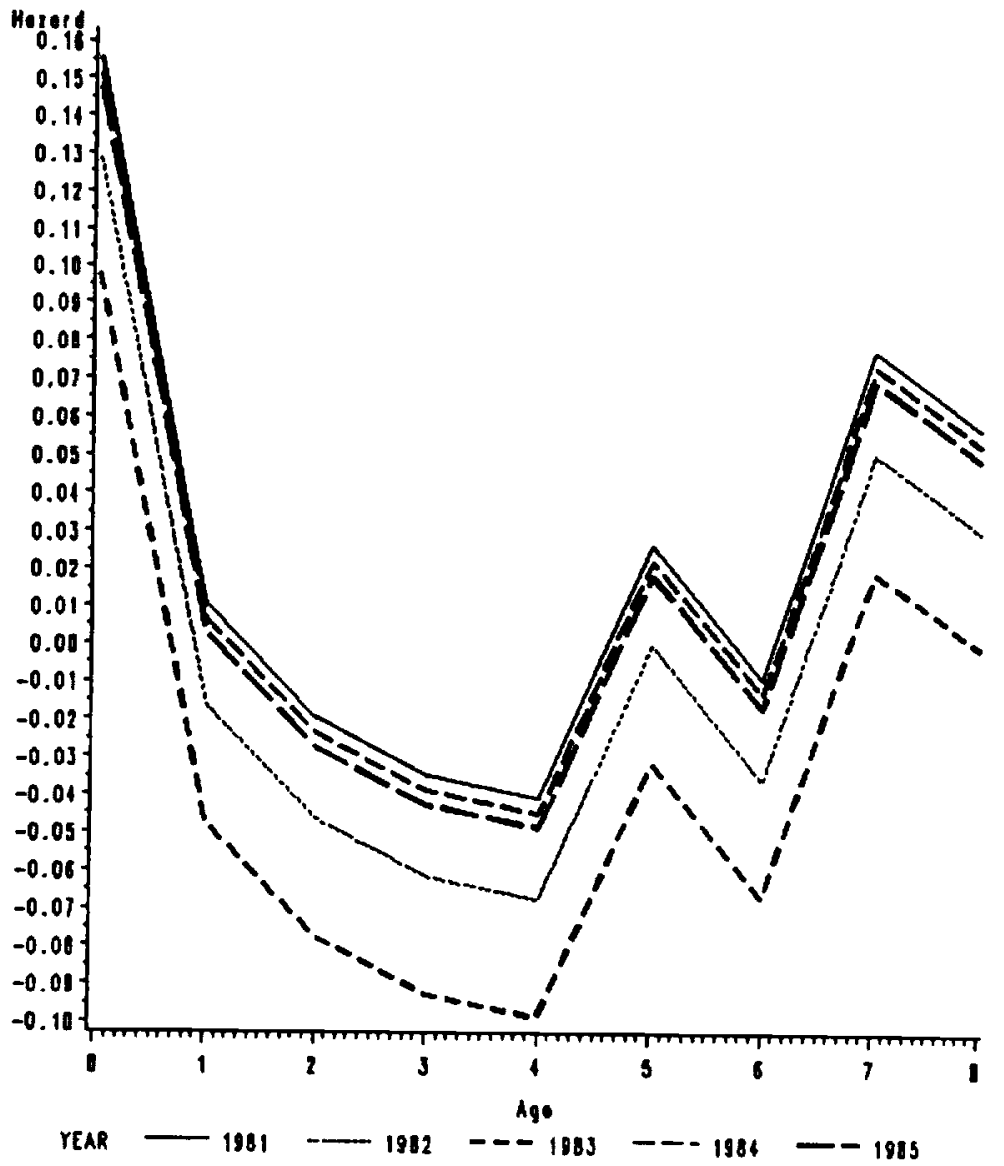




\section{Actual and Predicted Investment Spikes}

Investment

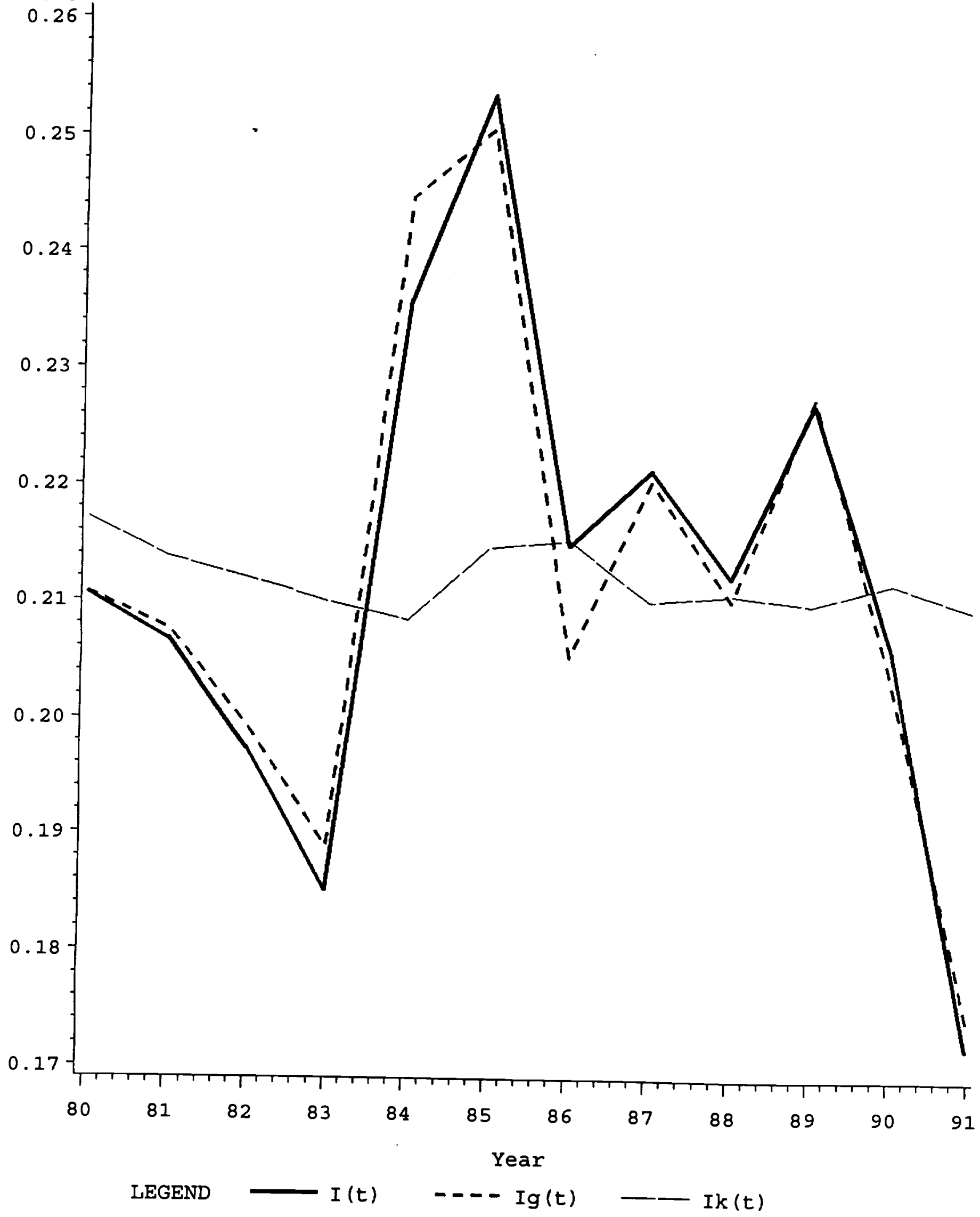


Figure 13

Actual Change Accounted for by Predicted Changes

Fraction

3

Actual Change

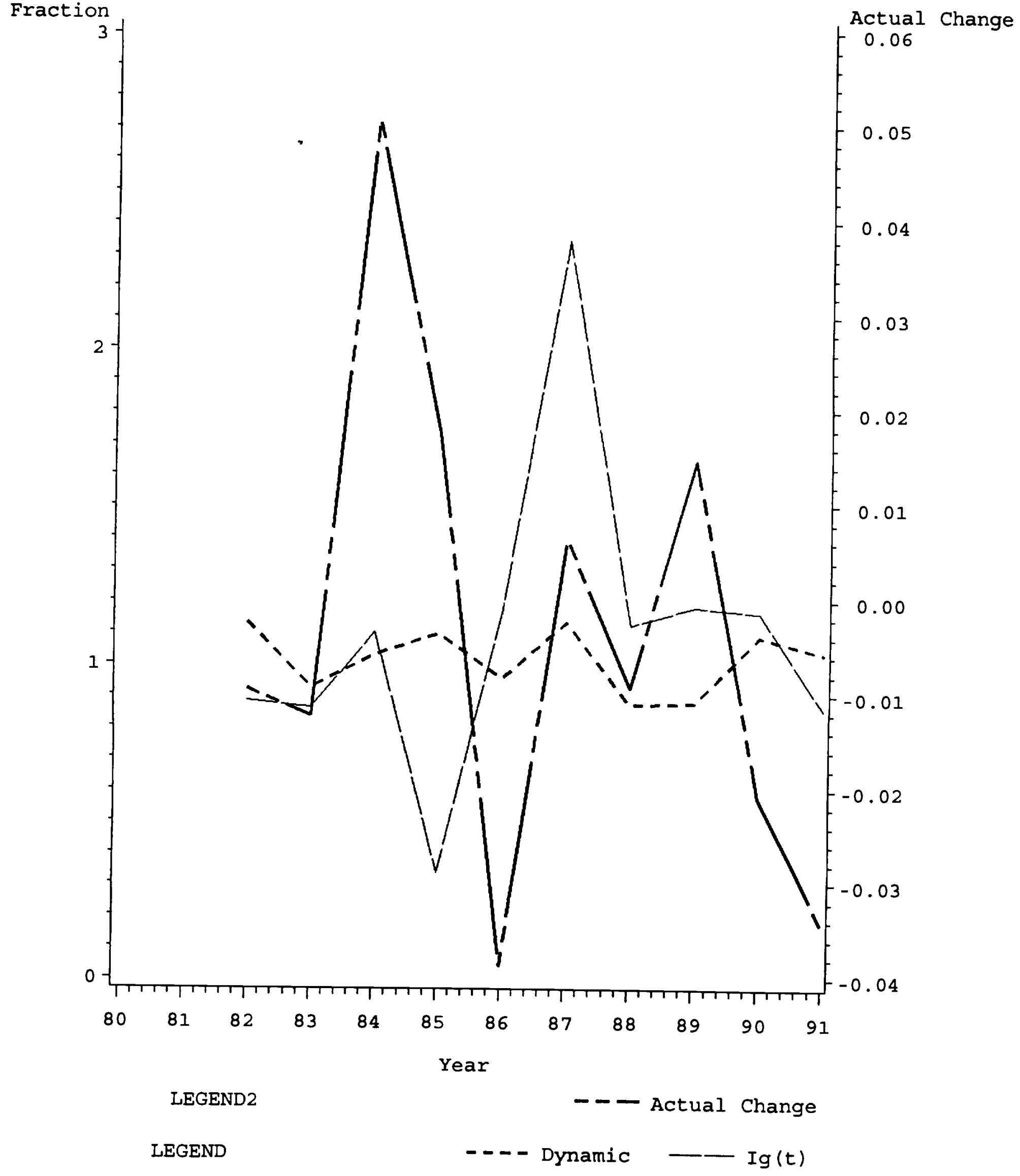

0.06

0.05

0.04

0.03

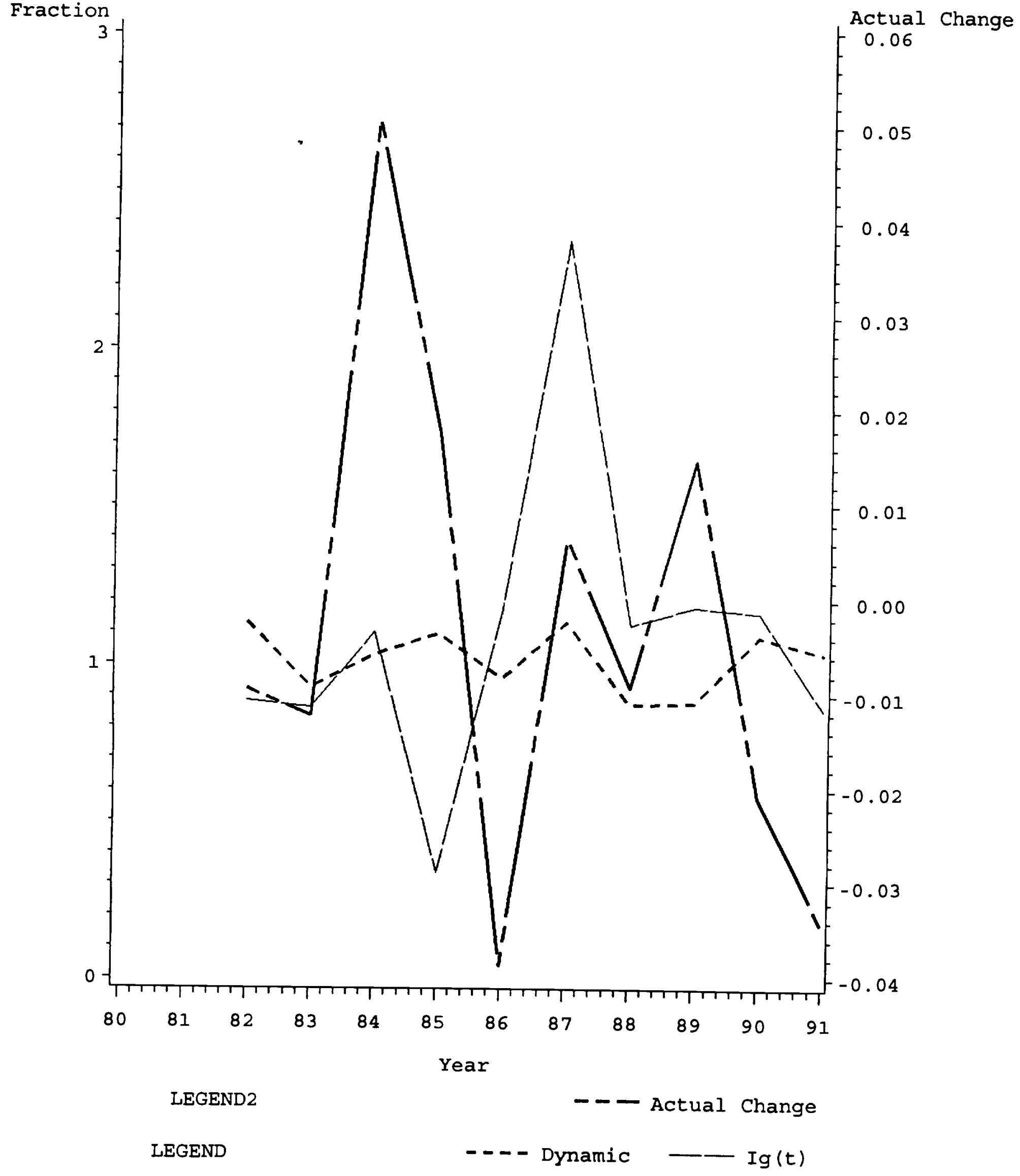

$-1$ 